Chapter 3

\title{
Polymer-Graphene Nanocomposites: Preparation, Characterization, Properties, and Applications
}

\author{
Kuldeep Singh, Anil Ohlan and S.K. Dhawan \\ Additional information is available at the end of the chapter \\ http://dx.doi.org/10.5772/50408
}

\section{Introduction}

Carbon the $6^{\text {th }}$ element in the periodic tables has always remains a fascinating material to the researcher and technologist. Diamond, graphite, fullerenes, carbon nanotubes and newly discovered graphene are the most studied allotropes of the carbon family. The significance of the these material can be understand as the discovery of fullerene and graphene has been awarded noble prizes in the years 1996 and 2010 to Curl, Kroto \& Smalley and Geim \& Novalec, respectively. After the flood of publications on graphite intercalated [1], fullerenes (1985) [2], and carbon nanotubes (1991) [3], graphene have been the subject of countless publications since 2004 [4,5]. Graphene is a flat monolayer of carbon atoms tightly packed into a two-dimensional (2D) honeycomb lattice, completely conjugated $\mathrm{sp}^{2}$ hybridized planar structure and is a basic building block for graphitic materials of all other dimensionalities (Figure 1). It can be wrapped up into $0 \mathrm{D}$ fullerenes, rolled into 1D nanotube or stacked into 3D graphite.

In 2004, Geim and co-workers at Manchester University successfully identified single layers of graphene in a simple tabletop experiment and added a revolutionary discovery in the field of nano science and nanotechnology. Interest in graphene increased dramatically after Novoselov, Geim et al. reported on the unusual electronic properties of single layers of the graphite lattice. One of the most remarkable properties of graphene is that its charge carriers behave as massless relativistic particles or Dirac fermions, and under ambient conditions they can move with little scattering. This unique behavior has led to a number of exceptional phenomena in graphene [4]. First, graphene is a zero-band gap 2D semiconductor with a tiny overlap between valence and conduction bands. Second, it exhibits a strong ambipolar electric field effect so that the charge carrier concentrations of up to $1013 \mathrm{~cm}^{-2}$ and room-temperature mobility of $\sim 10000 \mathrm{~cm}^{-2} \mathrm{~s}^{-1}$ are measured. Third, an unusual half-integer quantum Hall effect (QHE) for both electron and hole carriers in graphene has been observed by ad- 
justing the chemical potential using the electric field effect [5,6]. It has high thermal conductivity with a value of $\sim 5000 \mathrm{WmK}^{-1}$ for a single-layer sheet at room temperature. In addition, graphene is highly transparent, with absorption of $\sim 2.3 \%$ towards visible light [7, 8]. Narrow ribbons of graphene with a thickness of 1-2 $\mathrm{nm}$ are, however, semiconductors with a distinct band gap, and these can be used to produce transistors [9-11].

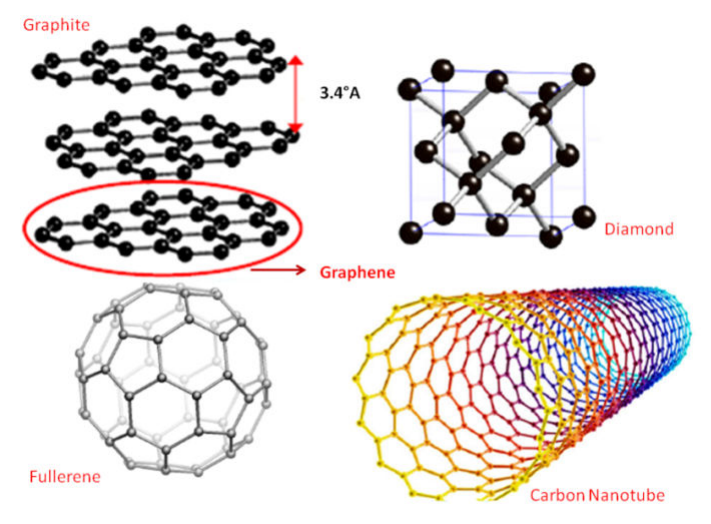

Figure 1. Different allotropes of carbon viz Graphite, Diamond, Fullerene, and Carbon nanotube

In last couples of years, graphene has been used as alternative carbon-based nanofiller in the preparation of polymer nanocomposites and have shown improved mechanical, thermal, and electrical properties [12-19]. The recent advances have shown that it can replace brittle and chemically unstable indium tin oxide in flexible displays and touch screens [20-21]. It is well established that the superior properties of graphene are associated with its single-layer. However, the fabrication of single-layer graphene is difficult at ambient temperature. If the sheets are not well separated from each other than graphene sheets with a high surface area tend to form irreversible agglomerates and restacks to form graphite through $\mathrm{p}-\mathrm{p}$ stacking and Vander Waals interactions [22,23]. Aggregation can be reduced by the attachment of other small molecules or polymers to the graphene sheets. The presence of hydrophilic or hydrophobic groups prevents aggregation of graphene sheets by strong polar-polar interactions or by their bulky size [24]. The attachment of functional groups to graphene also aids in dispersion in a hydrophilic or hydrophobic media, as well as in the organic polymer. Therefore, an efficient approach to the production of surface-functionalized graphene sheets in large quantities has been a major focus of many researchers. The goal is to exploit the most frequently proposed applications of graphene in the areas of polymer nanocomposites, super-capacitor devices, drug delivery systems, solar cells, memory devices, transistor devices, biosensors and electromagnetic/ microwave absorption shields. 


\section{Methods of Graphene Synthesis}

There have been continuous efforts to develop high quality graphene in large quantities for both research purposes and with a view to possible applications. The methods of preparation for graphene can be divided into two categories, top-down and bottom-up ones. The top-down methods include (1) mechanical exfoliation (2) chemical oxidation/exfoliation followed by reduction of graphene derivatives such as graphene oxide. While the bottom-up methods include (1) epitaxial growth on SiC and other substrates, (2) Chemical vapor deposition, and (3) arc discharging methods. Each of these methods has some advantages and limitations. Among them chemical synthesis of graphene using graphite, graphite oxide (GO) is a scalable process but it leads to more defent in the graphene layer.

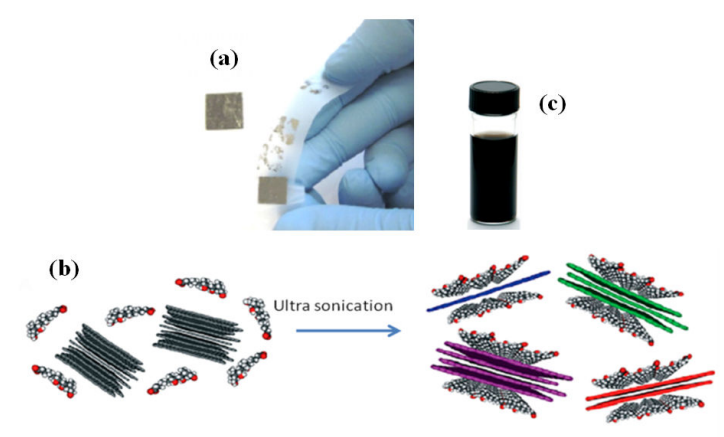

Figure 2. A) Mechanical exfoliation of graphene using scotch tape from HOPG (B) Schematic illustration of the graphene exfoliation process. Graphite flakes are combined with sodium cholate in aqueous solution. Horn-ultrasonication exfoliates few-layer graphene flakes that are encapsulated by sodium cholate micelles. \& (C) Photograph of 90 $\mu \mathrm{g} / \mathrm{ml}$ graphene dispersion in sodium cholate (Reprinted with permission from ref 25 Copyright.2009 American Chemical Society)

\subsection{Mechanical exfoliation}

The "perfect" graphene, necessary for the fundamental studies can be obtained by the mechanical exfoliation and epitaxial methods, but these methods have a limit for scale up. Mechanical exfoliation is a simple peeling process where a dried highly oriented pyrolytic graphite (HOPG) sheet are etched in oxygen plasma and then it is stuck onto a photo resist and peeled off layers by a scotch tape (Figure 2a). The thin flakes left on the photo resist were washed off in acetone and transferred to a silicon wafer. It was found that these thin flakes were composed of monolayer or a few layers of graphene [4].

\subsection{Chemical exfoliation and intercalation of small molecules:}

The first graphite intercalation compound (GIC), commonly known as expandable graphite was prepared by Schafhautl in 1841, while analyzing crystal flake of graphite in sulfuric acid solution. The intercalation of graphite by atoms or molecules such as alkali metals or miner- 
al acids increases its interlayer spacing, weakening the interlayer interactions and facilitating the exfoliation of GIC by mechanical or thermal methods (Figure 2b\& 2c) [25]. The intercalation of graphite by a mixture of sulfuric and nitric acid produces a higher-stage GIC that can be exfoliated by rapid heating or microwave treatment of the dried down powder, producing a material commonly referred to as expanded graphite [26]. It retained a layered structure but has slightly increased interlayer spacing relative to graphite and has been investigated as a composite filler [27-28]. However its effectiveness in enhancing the properties as compared to graphene oxide (GO) derived fliers is limited by its layered structure and relatively low specific surface area. To produce a higher surface area material, expanded graphite can be further exfoliated by various techniques to yield graphene nanoplates (GNPs) down to $5 \mathrm{~nm}$ thickness[29-30]. It has also been reported that sulfuric acid intercalated expanded graphite can be co-intercalated with tetrabutyl ammonium hydroxide. A monolayer like graphene can be obtained by sonicating the GIC in N,N-dimethylformamide (DMF) in the presence of a surfactant like poly(ethylene glycol)-modified phospholipid. Blake et al. and Hernandez et al.[31-32] have established a method for the preparation of defect free graphene by exfoliation of graphite in N-methyl-pyrrolidione. Such approach utilizes the similar surface energy of N-methyl-pyrrolidone and graphene that facilitates the exfoliation. However, the disadvantage of this process is the high cost of the solvent and the high boiling point of the solvent that makes the graphene deposition difficult. Lotya and coworkers have used a surfactant (sodium dodecyl benzene sulfonate, SDBS) to exfoliate graphite in water to produce graphene. The graphene monolayers are stabilized against aggregation by a relatively large potential barrier caused by the Coulomb repulsion between surfactant-coated sheets. The dispersions are reasonably stable with larger flakes precipitating out over more than 6 weeks [33].

\subsection{Chemical vapor deposition \& Epitaxial growth of graphene:}

Chemical vapor deposition (CVD) is alternatives method to mechanical exfoliation and used to obtain high quality graphene for large-scale production of mono or few layer graphene films on metal substrate[34-40]. The CVD processes generally utilize transition metal surfaces for growth of Graphene nanosheets (GNS) using hydrocarbon gases as GNS precursors at the deposition temperature of about $1000{ }^{\circ} \mathrm{C}$. Ruoff et al. reported a CVD method for large-area synthesis of high-quality and uniform GNS films on copper foils using a mixture of methane and hydrogen as precursors. As obtained films are predominantly single-layer GNS with a small percentage (less than $5 \%$ ) of the area having few layers, and continuous across copper surface steps and grain boundaries. Particularly, one of the major benefits of their process is that it could be used to grow GNS on $300 \mathrm{~mm}$ copper films on Si substrate and this GNS film could also be easily transferred to alternative substrates, such as $\mathrm{SiO}_{2} / \mathrm{Si}$ or glass. Recently, Bae and coworkers reported a roll-to-roll production of 30 inch (Figure 3) graphene films using the CVD approach [41].

Another technique for the GNS synthesis is Epitaxial growth on silicon carbide ( $\mathrm{SiC})$. It is a very promising method for the synthesis of uniform, wafer-size graphene nano layers, in which single crystal $\mathrm{SiC}$ substrates are heated in vacuum to high temperatures in the range 
of $1200-1600{ }^{\circ} \mathrm{C}$. Since the sublimation rate of silicon is higher than that of carbon, excess carbon is left behind on the surface, which rearranges to form GNS[42-44] More recently Bao et al has reported an interesting route for the preparation of GNS that employed commercial polycrystalline $\mathrm{SiC}$ granules instead of single-crystal $\mathrm{SiC} \mathrm{[45]} \mathrm{to} \mathrm{formulate} \mathrm{high-quality} \mathrm{free-}$ standing single-layer GNS.

\subsection{Chemically converted Graphene}

At present, the most viable method to afford graphene single sheets in considerable quantities is chemical conversion of graphite to graphene oxide followed by successive reduction [46-48]. Graphite oxide (GO) is usually synthesized through the oxidation of graphite using strong oxidants including concentrated sulfuric acid, nitric acid and potassium permanganate.

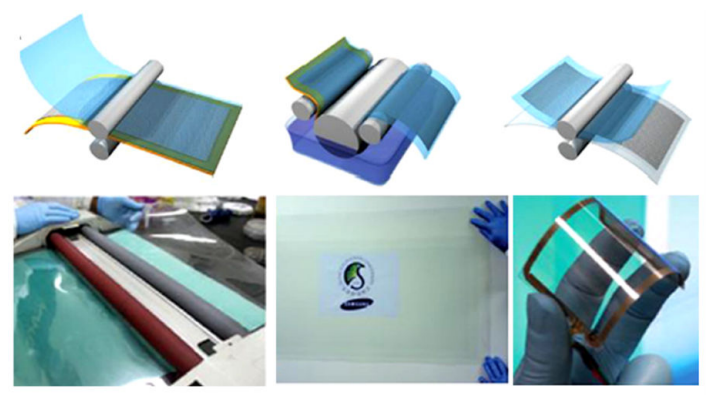

Figure 3. Schematic of the roll-based production of graphene films grown on a copper foil. A transparent ultra largearea graphene film transferred on a 35-in. PET sheet and an assembled graphene/PET touch panel showing outstanding flexibility. (Reprinted by permission from Macmillan Publishers Ltd: [Nature Nanotechnology] (ref 41: copyright (2010)

\subsubsection{Synthesis of graphene oxide and its reduction}

In 1859, Brodie was first to prepared graphite oxide by the oxidation of graphite with fuming nitric acid and potassium chlorate under cooling [49], In 1898, Staudenmaier improved this protocol by using concentrated sulfuric acid as well as fuming nitric acid and adding the chlorate in multiple aliquots over the course of the reaction. This small change in the procedure made the production of highly oxidized GO in a single reaction vessel [50]. In 1958, Hummers reported the method most commonly used today in which graphite is oxidized by treatment with $\mathrm{KMnO}_{4}$ and $\mathrm{NaNO}_{3}$ in concentrated $\mathrm{H}_{2} \mathrm{SO}_{4}$ [51]. These three methods comprise the primary routes for forming GO. Recently, an improved method was reported by Marcano et al. [52], they used $\mathrm{KMnO}_{4}$ as the only oxidant and an acid mixture of concentrated $\mathrm{H}_{2} \mathrm{SO}_{4}$ and $\mathrm{H}_{3} \mathrm{PO}_{4}$ (9:1) as the acidic medium. This technique greatly increased the efficiency of oxidizing graphite to $\mathrm{GO}$ and also prevented the formation of toxic gases, such as $\mathrm{NO}_{2}$ and $\mathrm{N}_{2} \mathrm{O}_{4}$. The graphene oxide prepared by this method is more oxidized than that prepared by Hummer's method and also possesses a more regular structure. Graphite can also be oxidized by benzoyl peroxide (BPO) at $110 \mathrm{C}$ for $10 \mathrm{~min}$ in an opened system 
(Caution! BPO is a strong oxidizer and may explode when heated in a closed container) to GO [53]. This technique provides a fast and efficient route to graphene oxide. The composition of anhydrous GO is approximately $\mathrm{C}_{8} \mathrm{O}_{2}(\mathrm{OH})_{2}$. Almost none of the carbon of the graphite used is lost during the formation of GO. Compared to pristine graphite, GO is heavily oxygenated bearing hydroxyl and epoxy groups on $\mathrm{sp}^{3}$ hybridized carbon on the basal plane, in addition to carbonyl and carboxyl groups located the sheet edges on $\mathrm{sp}^{2}$ hybridized carbon. Hence, GO is highly hydrophilic and readily exfoliated in water, yielding stable dispersion consisting mostly of single layered sheets (graphene oxide). It is important to note that although graphite oxide and graphene oxide share similar chemical properties (i.e. surface functional group), their structures are different. Graphene oxide is a monolayer material produced by the exfoliation of graphite oxide. Sufficiently dilute colloidal suspension of graphene oxide prepared by sonication are clear, homogeneous and stable indefinitely. AFM images of GO exfoliated by the ultrasonic treatment at concentrations of $1 \mathrm{mg} / \mathrm{ml}$ in water always revealed the presence of sheets with uniform thickness $(1 \mathrm{~nm})$. The pristine graphite sheet is atomically flat with the Vander Waals thickness of $0.34 \mathrm{~nm}$, graphene oxide sheets are thicker due to the displacement of $\mathrm{sp}^{3}$ hybridized carbon atoms slightly above and below the original graphene plane and presence of covalently bound oxygen atoms. A similar degree of exfoliation of GO was also attained for N,N-dimethylformamide (DMF), tetrahydrofuran (THF), N-methyl-2-pyrrolidone (NMP) and ethylene glycol [54]. Chung et al [55] has utilized the utilized a modified hummer method to produces a large sized highly functionalized graphene oxide, In a typical method a small amount of graphite was irradiated for $10 \mathrm{~s}$ in a microwave oven and expanded to about 150 times its original volume and carried out the further oxidation by modified Hummers method (Figure 4).

\subsubsection{Reduction of Graphene oxide}

As discussed the exfoliated sheets contain many hydrophilic functionality like - $\mathrm{OH}$, $-\mathrm{COOH},-\mathrm{C}-\mathrm{O}-\mathrm{C}-, \mathrm{C}=\mathrm{O}$ which keep them highly dispersible and the layered sheets are named graphene oxide (GO). The most attractive property of GO is that it can be reduced to graphene-like sheets by removing the oxygen-containing groups with the recovery of a conjugated structure. The reduced GO (RGO) sheets are usually considered as one kind of chemically derived graphene (CCG). It is a very promising candidate for many applications such as electronic devices [56,57], polymer composites [58-61], energy conversion, storage materials [62,63], and sensors [64]. The most desirable goal of any reduction procedure is produce graphene-like materials similar to the pristine graphene. Though numerous efforts have been made, the final target is still a dream. Residual functional groups and defects dramatically alter the structure of the carbon plane and affect its conductivity which mainly depend on the long-range conjugated network of the graphitic lattice $[65,66]$. Functionalization breaks the conjugated structure and localizes p-electrons, which results in a decrease of both carrier mobility and carrier concentration therefore, it is not appropriate to refer to RGO/CCG, simply as graphene since the properties are considerably different [67-72]. Several reducing agents have been used to reduce graphene oxide, such as hydrazine [73], sodium borohydride [74], hydroiodic acid [75,76], sulfur-containing compounds [77], ascorbic acid [78], and vitamin C[79] 


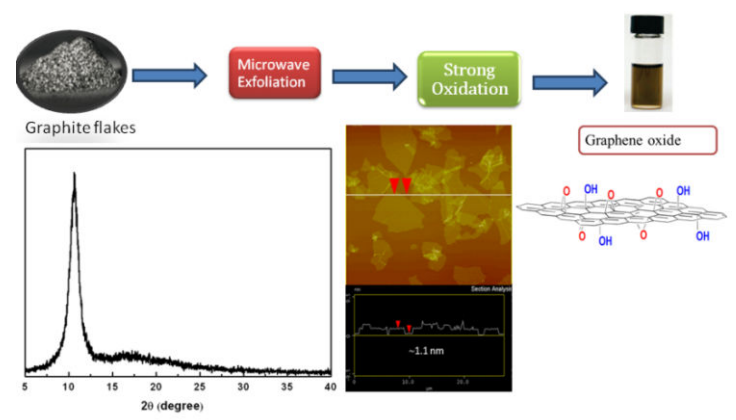

Figure 4. Scheme of synthesis of XRD and AFM image of GO.

Among them, hydrazine is widely used because it is an effective reducing agent and well suited to the reduction of graphene oxide in various media, including the aqueous phase, gas phase, and especially in organic solvents. The most obvious changes can be directly observed or measured to judge the reducing effect of different reduction processes. Since a reduction process can dramatically improve the electrical conductivity of GO, the increased charge carrier concentration and mobility will improve the reflection to incident light, and color changes to brown to black as shown in Figure 4. The variation of electrical conductivity of RGO can be a direct criterion to judge the effect of different reduction methods. Another important change is $\mathrm{C} / \mathrm{O}$ ratio is usually obtained through elemental analysis measurements by combustion, and also by X-ray photo-electron spectrometry (XPS) analysis. Depending on the preparation method, GO with chemical compositions ranging from $\mathrm{C}_{8} \mathrm{O}_{2} \mathrm{H}_{3}$ to $\mathrm{C}_{8} \mathrm{O}_{4} \mathrm{H}_{5}$, corresponding to a $\mathrm{C} / \mathrm{O}$ ratio of $4: 1-2: 1$, is typically produced [80,81]. After reduction, the $\mathrm{C} / \mathrm{O}$ ratio can be improved to approximately 12:1 in most cases, but values as large as 246:1 have been recently reported [82]. In addition to these other tools like Raman spectroscopy, solid-state FT-NMR spectroscopy, transmission electron microscopy (TEM), and atomic force microscopy (AFM), are most promising tools to show the structural changes of GO after reduction.

There are several routes to reduce the graphene oxide like thermal annealing, microwave and photo reduction, and chemical reduction (Chemical reagent reduction, Solvo-thermal reduction, Multi-step reduction, Electrochemical reduction, Photocatalyst reduction). Here we are only focusing on thermal annealing and solvo-thermal chemical reduction as these are most wide used method for the reduction.

\subsubsection{Thermal annealing}

GO can be reduced by thermal annealing and a temperature less than $2000{ }^{\circ} \mathrm{C}$ was used in the initial stages of graphene research, to exfoliate graphite oxide to achieve graphene [83 84]]. The mechanism of exfoliation is mainly the sudden expansion of $\mathrm{CO}$ or $\mathrm{CO}_{2}$ gases evolved into the spaces between graphene sheets during rapid heating of the graphite oxide. However, this technique is not so promising as it leads to the structural damage to graphene 
sheets caused by the release of carbon dioxide [85]. Approximately $30 \%$ of the mass of the graphite oxide is lost during the exfoliation process, leaving behind lattice defects throughout the sheet [83]. As a result, the electrical conductivity of the graphene sheets has a typical mean value of $10-23 \mathrm{~S} / \mathrm{cm}$ that is much lower than that of perfect graphene, indicating a weak effect on reduction and restoration of the electronic structure of carbon plane.

An alternative way is to exfoliate graphite oxide in the liquid phase, which enables the exfoliation of graphene sheets with large lateral sizes [86]. The reduction is carried out after the formation of macroscopic materials, e.g. films or powders, by annealing in inert or reducing atmospheres. In this strategy, the heating temperature significantly affects reduction of GO. Schniepp et al [83] found that if the temperature was less than $500{ }^{\circ} \mathrm{C}$, the $\mathrm{C} / \mathrm{O}$ ratio was not more than 7 , while if the temperature reached $750^{\circ} \mathrm{C}$, the $\mathrm{C} / \mathrm{O}$ ratio could be higher than 13 . The reduced GO film obtained at $500{ }^{\circ} \mathrm{C}$ was only $50 \mathrm{~S} / \mathrm{cm}$, while for those at 700 and 1100 ${ }^{\circ} \mathrm{C}$ it could be 100 and $550 \mathrm{~S} / \mathrm{cm}$ respectively. In addition to annealing temperature, annealing atmosphere is important for the thermal annealing reduction of GO. Since the etching of oxygen will be dramatically increased at high temperatures, oxygen gas should be excluded during annealing. As a result, annealing reduction is usually carried out in vacuum [87], or an inert [88] or reducing atmosphere [89].

\subsubsection{Chemical reduction}

Chemical reduction has been evaluated as one of the most efficient methods for low-cost, large-scale production of Graphene. Another advantage of chemical reduction methods is that the produced GNS in the form of a monolayer can be conveniently deposited on any substrate with simple processing. The chemical reduction method involves graphite oxidation by a strong oxidant to create graphene oxide, which is subsequently reduced by reducing agents [90-94] thermal [94], solvo-thermal [95-98], or electrochemical [99] methods to produce chemically modified graphene. Among these reduction processes, hydrazine reduction and solvo-thermal reduction can create process able colloidal dispersions of reduced graphene oxide, which may be used in a wide range of applications. Chemical reduction using hydrazine is one of the most effective methods for converting graphene oxide to chemically converted graphene (CCG). Chung at al [100] has report a simple and effective method for reducing and functionalizing graphene oxide into chemically converted graphene by solvo-thermal reduction of a graphene oxide suspension in N-methyl-2-pyrrolidone (NMP). NMP is a powerful solvent for dispersing SWCNT and graphene and high boiling point $\left(\sim 202{ }^{\circ} \mathrm{C}\right)$ of NMP facilitates the use of NMP as a solvent for solvo-thermal reduction in open systems. Dubin et al. [101] reported solvo-thermally reduced graphene oxide suspension in NMP for $24 \mathrm{~h}$ at $200{ }^{\circ} \mathrm{C}$ under oxygen-free conditions. As obtained, graphene was well dispersed in various solvents such as dimethylsulfoxide, ethyl acetate, acetonitrile, ethanol, tetrahydrofuran (THF), DMF, chloroform, and acetone with minimum precipitation at $1 \mathrm{mg} / \mathrm{ml}$ after 6 weeks.

However, the electrical conductivity of free-standing paper of graphene prepared by filtration was very low i.e. $374 \mathrm{~S} / \mathrm{m}$, when dried in air and $1380 \mathrm{~S} / \mathrm{m}$, when dried at $250{ }^{\circ} \mathrm{C}$. Recently Chung et al. have report the superior disersibility of RGO in N,N-dimethylformamide 
(DMF) by controlling the conditions of the hydrazine reduction. Instead of reducing the graphene oxide using hydrazine at high temperature $\left(80-100^{\circ} \mathrm{C}\right)$ excess amounts of hydrazine were used. Reduction was carried out at ambient temperature to achieve extensive reduction with a C/O ratio of approximately 9.5, which is comparable to previous reports, while the RGO disersibility in NMP was as high as $0.71 \mathrm{mg} / \mathrm{mL}$. The key to achieve highly dispersed RGO is performing the hydrazine reduction of graphene oxide at low temperature, which minimizes the formation of irreversible RGO aggregates [102]. Notably, the electrical conductivity of the hydrazine reduced graphene (HRGs) was sharply and inversely proportional to the dispersibility in DMF.

\section{Conducting Polymer-graphene composite}

Nanocomposites have been investigated since 1950, but industrial importance of the nanocomposites came nearly forty years later following a report from researchers at Toyota Motor Corporation that demonstrated large mechanical property enhancement using montmorillonite as filler in a Nylon-6 matrix and new applications of polymers. A nanocomposite is defined as a material with more than one solid phase, metal ceramic, or polymer, compositionally or structurally where at least one dimension falls in the nanometers range. Most of the composite materials are composed of just two phases; one is termed the matrix, which is continuous and surrounds the other phase, often called the dispersed phase and their properties are a function of properties of the constituent phases, their relative amounts, and the geometry of the dispersed phase. The combination of the nanomaterial with polymer is very attractive not only to reinforce polymer but also to introduce new electronic properties based on the morphological modification or electronic interaction between the two components. Depending on the nature of the components used and the method of preparation, significant differences in composite properties may be obtained. Nanocomposites of conducting polymers have been prepared by various methods such as colloidal dispersions, electrochemical encapsulation coating of inorganic polymers, and insitu polymerization with nanoparticles and have opened new avenues for material synthesis [103-105].

Conducting polymer composites with graphite, CNT, Metal/metal oxides are studied a lot because of their usual electrical and mechanical properties. For example, In case of electromagnetic interference shielding application, the combination of magnetic nanoparticles with conducting polymer leads to form a ferromagnetic conducting polymer composite possessing unique combination of both electrical and magnetic properties. This type of materials can effectively shield electromagnetic waves generated from an electric source. When conducting polymers are combined with carbons material like CNT graphite and graphene they show good thermal and electrical properties as electronic conduction occurs at long range. In last couples of years, a variety of processing routes have been reported for dispersing the graphene based and it derivative as fillers in the polymer matrices. Many of these procedures are similar to those used for other nanocomposite systems but some are different and unique and have enhanced the bonding interaction at the interface between the filler and matrix significantly. Most of the dispersion methods produce composites by non-covalent 
assemblies where the polymer matrix and the filler interact through relatively weak dispersive forces. However, there is a growing research focus on introducing covalent linkages between graphene-based filler and the supporting polymer to promote stronger interfacial bonding. It is well known that most of the $\pi$-conjugated conducting polymers (CPs) are quite different from classical insulating polymers. They have conjugated backbones, which provide them with unique electrical and optical properties. These polymers are conductive in their doped states while insulating in their neutral states. Furthermore they are usually brittle, weak in mechanical strengths and usually insoluble, intractable and decompose before melting, having poor processability [104]. Thus, CP/CCG composites were mostly prepared by in situ polymerizations using different approaches. The incorporation of CCG into conducting polymer is attractive for combining the properties of both components or improving the properties of resulting composites based on synergy effects. The major forerunner of conducting polymer family are polyaniline (PANI), polypyrrole (PPy), polythiophene and poly(3,4-ethylenedioxythiophene) PEDOT and most of the research work has been done on them, polyaniline [105,106-111], PPy [112], poly(3-hexylthiophene) (P3HT) [113], PEDOT [1114] have been hybridized with CCG to form composites.

\subsection{In-situ polymerization}

In situ polymerization combines a post-graphitization strategy and is most widely applied method for preparing CCG/CP composites. Most of the work is done on PANI as it has good environmental stability, reversible redox activity, and potential applications in sensing, energy conversion and storages and electromagnetic shielding application [109,110-111,115]. Graphene oxide/PANI composites can be prepared by polymerizing aniline in graphene oxide dispersion. After the reduction of GO with hydrazine, the corresponding composites with CCG can be obtained. The key point to note here is that, the polymerization must be carried out in an acidic medium $(\mathrm{pH} \sim 1)$ for producing high-quality PANI. However, over acidification of the solution will cause clogging of graphene oxide sheets. Thus, the $\mathrm{pH}$ value of the reaction system must be optimized carefully. A graphene oxide-polypyrrole composite was also prepared by in situ polymerization in water in the presence of a surfactant [116-120] although graphene oxide was not converted to CCG, the composite exhibited a higher electrical conductivity than pure PPy.

Graphene has a tendency of aggregation and shows poor solubility, is the dominant factor for limiting the application of this technique. In this case, special care should be taken to avoid the precipitation of CCG, especially when oxidant was added. In another work, Xu and Chen et al. polymerized 3,4-ethylenedioxythiophene (EDOT) in the dispersion of sulfonated graphene, giving a CCG/PEDOT composite [121]. They claimed that sulfonate groups could increase the solubility of CCG and acted as dopants of PEDOT.

\subsection{Solution mixing}

A very less number of research articles are available on the preparation of CCG/CP composites using solution mixing in comparison to insitu polymerization as most of the CPs are insoluble in common solvent. However, the solubility or dispersibility of CPs can be im- 
proved by chemical modifications or fabricating them into nanostructures. On the basis of this idea, CCG/sulfonated PANI (SPANI) [122] can be recognized as conjugated polyelectrolytes (CPE) according to their chain structures. The strong $\pi-\pi$ interaction between the $\mathrm{CPE}$ chains and the basal planes of CCG sheets enables the composites to form stable dispersions. Composite films can be fabricated by casting the blend solutions. Graphene oxide was also reduced in an organic solvent with the presence of $\mathrm{P} 3 \mathrm{HT}$, giving a CCG/P3HT composite. Transparent and conductive film of graphene -polymer composite can be spin-coated or evaporated to produce composite films and can be used as the counter electrode of a dyesensitized solar cell [123-125].

\subsection{Covalent Grafting of polyaniline on graphene sheet}

Recently Kumar et al [126] has reported the covalent functionalization of amine-protected 4aminophenol to acylated graphene oxide and simultaneously reduced and in-situ polymerized in the presence of aniline monomer and produces a highly conducting networks. In this the oxygen containing functional groups on the surface of graphene oxide make it easily dispersible in aqueous solution and act as nucleation sites for producing PANI on its surfaces. The fabrication of PANI-grafted RGO (PANI-g-RGO was carried out in three steps as shown in Figure 5.

First the GO was synthesized by modified Hummers method and acylated in the presence of excess $\mathrm{SOCl}_{2}$ and then reacted with amine-protected 4-aminophenol. Futher, deprotection of $\mathrm{N}$-(tert-butoxycarbonyl) groups by hydrolysis with trifluoroacetic acid. PANI-g-RGO was prepared from in-situ oxidative polymerization of aniline in the presence of an oxidant and amine-terminated RGO (RGO- $\mathrm{NH}_{2}$ ) as an initiator. SEM image of the GO (Figure 6a) shows the layer-by-layer structure in stacking with a size of micrometers while PANI-g-RGO hybrid show typical fibrillar morphology (Figure $6 \mathrm{~b}$ and $6 \mathrm{c}$ ), where in some areas the composites exhibit mainly an irregular morphology with multiple shapes including both fibrillar and a few rod-like structures. In some places embedded flakes of graphene in PANI matrix are seen, suggesting graphene interconnection with the polymer network and forming a highly conducting network. The electrical conductivity of these hybrid assemblies was observed as high as $8.66 \mathrm{~S} / \mathrm{cm}$. HR-TEM images of GO exhibit a transparent layered and wrinkled silk-like structure, representing a curled and corrugated morphology intrinsically associated with graphene. Interestingly, the TEM image (Figure 7d) showed a typical single layer GO sheet. After functionalization, tremendous changes in morphology have been observed which basically arises by the introduction of aminophenol (Figure 6e) and PANI (Figure 7f) on the RGO surfaces. As for the PANI-g-RGO composite (Figure 7c), the coating of PANI is clearly visible, and it clearly distinguishes itself from the highly crystalline graphitic support, which is attributed to the surrounding of PANI on the RGO host. 


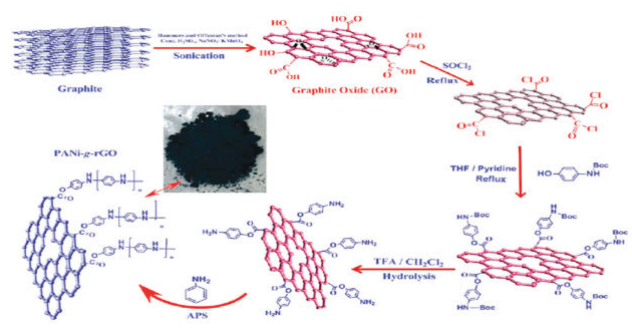

Figure 5. Scheme of direct grafting of polyaniline on the reduced graphene sheets (Reprinted with permission from ref 126 Copyright 2012 American Chemical Society)

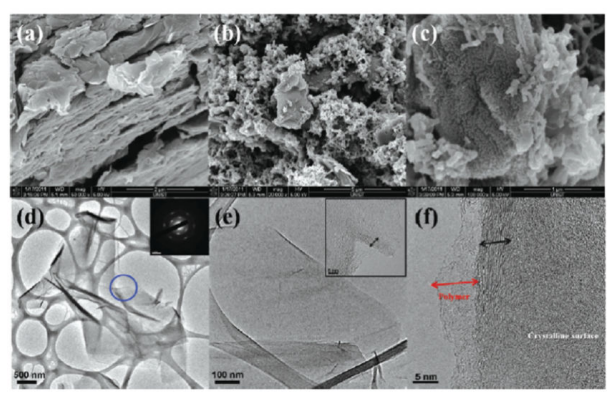

Figure 6. Typical FE-SEM images: (a) GO; (b and c) the surface of the PANI-g-RGO hybrid. HR-TEM images: (d) GO. Inset image is of a selected-area electron diffraction (SAED) pattern; (e) $\mathrm{RGO}-\mathrm{NH}_{2}$. Inset image is at higher magnification; ( $f$ ) PANI-g-RGO. (Reprinted with permission from ref 126 Copyright 2012 American Chemical Society)

\section{Application of conducting polymer graphene composites in EMI shielding}

Graphene being a two-dimensional (2D) structure of carbon atoms own exceptional chemical, thermal, mechanical, and electrical properties and mechanical properties. Extensive research has shown the potential of graphene or graphene-based sheets to impact a wide range of technologies. In this section, graphene based conducting polymer composites are discussed focusing their use an Electromagnetic interference shielding material [127-130].

The development made in the Nano sciences \& nanotechnology had flourished the electronic industries. Electronic systems have compact with increased the density of electrical components within an instrument. The operating frequencies of signals in these systems are also increasing and have created a new kind of problem called electromagnetic interference (EMI). Unwanted EMI effects occur when sensitive devices receive electromagnetic radiation that is being emitted whether intended or not, by other electric or electronic devices such as microwaves, wireless computers, radios and mobile phones. As a result, the affected 
receiving devices may malfunction or fail. The effects of electromagnetic interference are becoming more and more pronounced, caused by the demand for high-speed electronic devices operating at higher frequencies, more intensive use of electronics in computers, communication equipment and the miniaturisation of these electronics. For example, mobile phones and smartphones are typically operating at 2-3 GHz for data transmission through Universal Mobile Telecommunications Systems (UMTS). Compact, densely packed electronic components produce more electronic noise. Due to the increase in use of high operating frequency and band width in electronic systems, especially in X-band and broad band frequencies, there are concerns and more chances of deterioration of the radio wave environment. These trends indicate the need to protect components against electromagnetic interference (EMI) in order to decrease the chances of these components adversely affecting each other or the outer world. The effects of electromagnetic interference can be reduced or diminished by positioning a shielding material between the source of the electromagnetic field and the sensitive component. Shielding can be specified in the terms of reduction in magnetic (and electric) field or plane-wave strength caused by shielding. The effectiveness of a shield and its resulting EMI attenuation are based on the frequency, the distance of the shield from the source, the thickness of the shield and the shield material. Shielding effectiveness (SE) is normally expressed in decibels $(\mathrm{dB})$ as a function of the logarithm of the ratio of the incident and exit electric $(\mathrm{E})$, magnetic $(\mathrm{H})$, or plane-wave field intensities $(\mathrm{F})$ : SE $(\mathrm{dB})=20 \log \left(\mathrm{E}_{\mathrm{o}} / \mathrm{E}_{1}\right), \mathrm{SE}(\mathrm{dB})=20 \log \left(\mathrm{H}_{\mathrm{o}} / \mathrm{H}_{1}\right)$, or $\mathrm{SE}(\mathrm{dB})=20 \log \left(\mathrm{F}_{\mathrm{o}} / \mathrm{F}_{1}\right)$, respectively. With any kind of electromagnetic interference, there are three mechanisms contributing to the effectiveness of a shield. Part of the incident radiation is reflected from the front surface of the shield, part is absorbed within the shield material and part is reflected from the shield rear surface to the front where it can aid or hinder the effectiveness of the shield depending on its phase relationship with the incident wave, as shown in Figure 7

Therefore, the total shielding effectiveness of a shielding material (SE) equals the sum of the absorption factor $\left(\mathrm{SE}_{\mathrm{A}}\right)$, the reflection factor $\left(\mathrm{SE}_{\mathrm{R}}\right)$ and the correction factor to account for multiple reflections $\left(\mathrm{SE}_{\mathrm{M}}\right)$ in thin shields

$$
\mathrm{SE}=\mathrm{SE}_{\mathrm{A}}+\mathrm{SE}_{\mathrm{R}}+\mathrm{SE}_{\mathrm{M}}
$$

All the terms in the equation are expressed in $\mathrm{dB}$. The multiple reflection factor $\mathrm{SE}_{\mathrm{M}}$, can be neglected if the absorption loss $\mathrm{SE}_{\mathrm{A}}$ is greater than $10 \mathrm{~dB}$. In practical calculation, $\mathrm{SE}_{\mathrm{M}}$ can also be neglected for electric fields and plane waves.

\subsection{Absorption Loss}

Absorption loss $\mathrm{SE}_{\mathrm{A}}$, is a function of the physical characteristics of the shield and is independent of the type of source field. Therefore, the absorption term $\mathrm{SE}_{\mathrm{A}}$ is the same for all three waves. As shown in Figure 8, when an electromagnetic wave passes through a medium its amplitude decreases exponentially. This decay or absorption loss occurs because currents induced in the medium produce ohmic losses and heating of the material, where $\mathrm{E}_{1}$ and $H_{1}$ can be expressed as $E_{1}=E_{0} e^{-t / \delta}$ and $H_{1}=H_{o} e^{-t / \delta}$. The distance required by the wave 
to be attenuated to $1 / \mathrm{e}$ or $37 \%$ is defined as the skin depth. Therefore, the absorption term $\mathrm{SE}_{\mathrm{A}}$ in decibel is given by the expression:

$$
\mathrm{SE}_{\mathrm{A}}=20(t / \delta) \log e=8.69(t / \delta)=131 . t \sqrt{f \mu \sigma}
$$

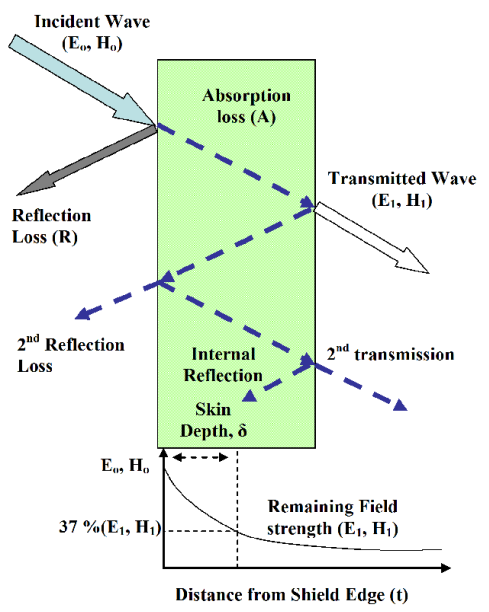

Figure 7. Graphical representation of EMI shielding

where, $\mathrm{t}$ is the thickness of the shield in $\mathrm{mm}$; $\mathrm{f}$ is frequency in $\mathrm{MHz} ; \mu$ is relative permeability ( 1 for copper); $\sigma$ is conductivity relative to copper. The skin depth $\delta$ can be expressed as:

The absorption loss of one skin depth in a shield is approximately $9 \mathrm{~dB}$. Skin effect is especially important at low frequencies, where the fields experienced are more likely to be predominantly magnetic with lower wave impedance than $377 \Omega$. From the absorption loss point of view, a good material for a shield will have high conductivity and high permeability along with a sufficient thickness to achieve the required number of skin depths at the lowest frequency of concern.

$$
\delta=\frac{1}{\sqrt{\pi f \mu \sigma}}
$$

\subsection{Reflection Loss}

The reflection loss is related to the relative mismatch between the incident wave and the surface impedance of the shield. The computation of refection losses can be greatly simplified by considering shielding effectiveness for incident electric fields as a separate problem from that of electric, magnetic or plane waves. The equations for the three principle fields are given by the expressions 


$$
\begin{gathered}
R_{E}=K_{1} 10 \log \left(\frac{\sigma}{f^{3} r^{2} \mu}\right) \\
R_{H}=K_{2} 10 \log \left(\frac{f r^{2} \sigma}{\mu}\right) \\
R_{P}=K_{3} 10 \log \left(\frac{f \mu}{\sigma}\right)
\end{gathered}
$$

where, $R_{E}, R_{H}$, and $R_{P}$ are the reflection losses for the electric, magnetic and plane wave fields, respectively, expressed in $\mathrm{dB}$; $\sigma$ is the relative conductivity relative to copper; $\mathrm{f}$ is the frequency in $\mathrm{Hz} ; \mu$ is the relative permeability relative to free space; $r$ is the distance from the source to the shielding in meter.

\subsection{Multiple Reflections}

The factor $\mathrm{SE}_{\mathrm{M}}$ can be mathematically positive or negative (in practice, it is always negative) and becomes insignificant when the absorption loss $\mathrm{SE}_{\mathrm{A}}>6 \mathrm{~dB}$. It is usually only important when metals are thin and at low frequencies (i.e., below approximately $20 \mathrm{kHz}$ ). The formulation of factor $\mathrm{SE}_{\mathrm{M}}$ can be expressed as

$$
S E_{M}=-20 \log \left(1-e^{-2 t / \delta}\right)
$$

Due to their high electrical conductivity, metals are particularly suitable as shielding material against electromagnetic fields. This can be a self-supporting full metal shielding, but also a sprayed, painted or electro-less applied conducting coating (e.g. nickel) on a supporting material such as plastic. Another option is the incorporation of metal (stainless steel) powder or fibres as conducting filler in a plastic matrix.

However, there are a certain draw backs to use metal as a shielding material. The weight of the 'heavy' metal can be an issue in the case of full metal shielding, processing and corrosion are other draw back to prohibit their use. In order to produce metal coatings, at least two processing techniques have to be applied one for the support and one for the coating, which can be costly. It will also be difficult to apply these coatings onto complicated shaped objects. In addition, the long-term adhesion of the coating to the support has to be reliable.

To solve the EMI problems, spinel-type ferrites, metallic magnetic materials, and carbon nanotube (CNT) composites [131-138] have been extensively studied. To achieve higher SE and to overcome the drawbacks of the metal-based art, polymer material with appropriate conductive fillers can be shaped into an EMI shielding substrate, which exhibit improved EMI shielding and absorption properties. The conductive composites in the form of coatings, strips or molded materials have been prepared by the addition of highly conductive fillers or powders to non-conductive polymer substrates. Conductive polymer composites give a significantly 
better balance of mechanical and electrical properties than some of the current generation of commercially available EMI-shielding material. It is observed that the high conductivity and dielectric constant of the materials contribute to high EMI shielding efficiency (SE). The combination of conducting polymer with nanostructured ferrite along with graphene offers potentials to fight with EM pollution. Recently Dhawan et al have reported that if magnetic particles of barium ferrite or $\mathrm{Fe}_{2} \mathrm{O}_{3}$ are incorporated in the polymer matrix they improve the magnetic and dielectric properties of host materials [139-141]. Therefore, conjugated polymers combined with magnetic nanoparticles to form ferromagnetic nanocomposites provide an exciting system to investigate the possibility of exhibiting novel functionality. The unique properties of nanostructured ferrite offer excellent prospects for designing a new kind of shielding materials. The absorption loss in the material is caused by the heat loss under the action between electric dipole and/or magnetic dipole in the shielding material and the electromagnetic field so that the absorption loss is the function of conductivity and the magnetic permeability of the material. The designing of ferrite based conducting polymer nanocomposites increases the shielding effectiveness. Conducting and magnetic properties of conducing polymer-ferrite nanocomposites can be tuned by suitable selection of polymerization conditions and controlled addition of ferrite nanoparticles. The contribution to the absorption value comes mainly due the magnetic losses $\left(\mu^{\prime \prime}\right)$ and dielectric losses $\left(\varepsilon^{\prime \prime}\right)$. The dependence of $\mathrm{SE}_{\mathrm{A}}$ on magnetic permeability and conductivity demonstrates that better absorption value has been obtained for material with higher conductivity and magnetization. Therefore, it has been concluded that the incorporation of magnetic and dielectric fillers in the polymer matrix lead to better absorbing material which make them futuristic radar absorbing material.

\section{Preparation of conducting polyaniline- graphene/ ferrite Composites}

There are many methods for the preparation of conducting polyaniline (PANI) like chemical or electrochemical oxidation of a monomer where the polymerization reaction is stoichiometric in electrons. However, number of methods such as photochemical polymerization, pyrolysis, metal-catalyzed polymerization, solid-state polymerization, plasma polymerization, ring-forming condensation, step-growth polymerization, and soluble precursor polymer preparation, have been reported in literature for synthesis of conjugated polymers. However, as discussed earlier good quality of polymer graphene composite can synthesized in-situ polymerization technique [140].

\subsection{Synthesis of nanocomposites}

Prior to the synthesis of polyaniline graphene composite, graphene oxide was synthesis using modified Hummers method followed by hydrazine reduction at $80{ }^{\circ} \mathrm{C}$ to get CCG/RGO and in-situ polymerized can carried out. The Oxidative polymerization of aniline in aqueous acidic media using ammonium persulfate as an oxidant is the most common and widely 
used method [141]. However by taking cationic or anionic surfactant one can easily controlled the morphology of the polymer. Therefore, emulsion polymerization is an appropriate method as the polymerization reaction takes place in a large number of loci dispersed in a continuous external phase. In a typical synthesis process, functional protonic acid such as dodecyl benzene sulfonic acid (DBSA) is used which being a bulky molecule, can act both as a surfactant and as dopant. The polymerization of aniline monomer in the presence DBSA (dodecyl benzene sulfonic acid) leads to the formation of emeraldine salt form of polyaniline. When the graphene nanosheets are dispersed and homogenized with DBSA in aqueous solution, micelles are formed over the graphene sheets. Anilinium cations sit between the individual DBSA molecules near the shell of the micelle complexed with sulfonate ion. When polymerization proceeds, anilinium cations are polymerized within the micelle with DBSA $\&$ over the graphene sheets resulting in the formation of polyaniline graphene composite. Pictorial representation for the formation of polyaniline-graphene composite is shown in figure 8. The same methodology can be used to prepare ferromagnetic conducting polymer graphene composite.

Here key to synthesized good quality of polymer composite is the weight ratio of ferrite and graphene to monomer. In this process, water is the continuous phase and DBSA is a surfactant that acts as discontinuous phase. Monomer aniline is emulsified to form the micro micelles of oil in water type. The shape of a micelle is a function of the molecular geometry of its surfactant molecules and solution conditions such as surfactant concentration, temperature, $\mathrm{pH}$ and ionic strength. Addition of the APS to the aniline monomer leads to the formation of cation radicals which combine with another monomer moiety to form a dimer, which on further oxidation and combination with another cation radical forms a termer and ultimately to a long chain of polymer.

Recently our group has synthesized the graphene oxide coated $\mathrm{Fe}_{2} \mathrm{O}_{3}$ nanoparticles and prepared polyaniline GO- $\mathrm{Fe}_{2} \mathrm{O}_{3}$ ( $\mathrm{PGF}$ ) nanocomposite by the same procedure as depicted in scheme (Figure 9 ) and reports the SE and dielectric measurement. Here we have varied the weight ratio of monomer to $\gamma-\mathrm{Fe}_{2} \mathrm{O}_{3}$ as An: GO: $\gamma-\mathrm{Fe}_{2} \mathrm{O}_{3}$ : 1:1:1 (PGF11), 1:1:2 (PGF12) and compared results with pristine polyaniline doped with DBSA (PD13) without ferrite particles and GO/polyaniline composite having weight ratio of aniline: GO in 2:1 (PG21) has also been synthesized in similar manner. 


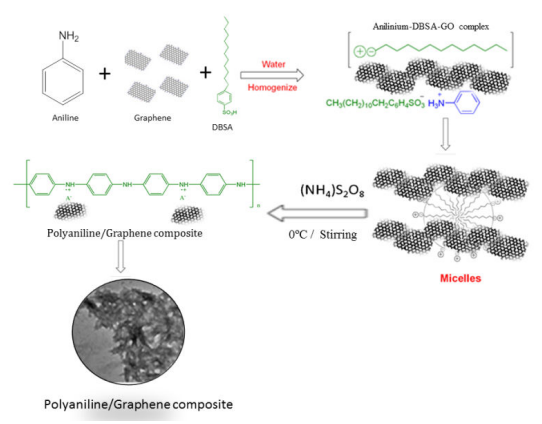

Figure 8. Schematic representation of the polymerization of graphene polyaniline composite

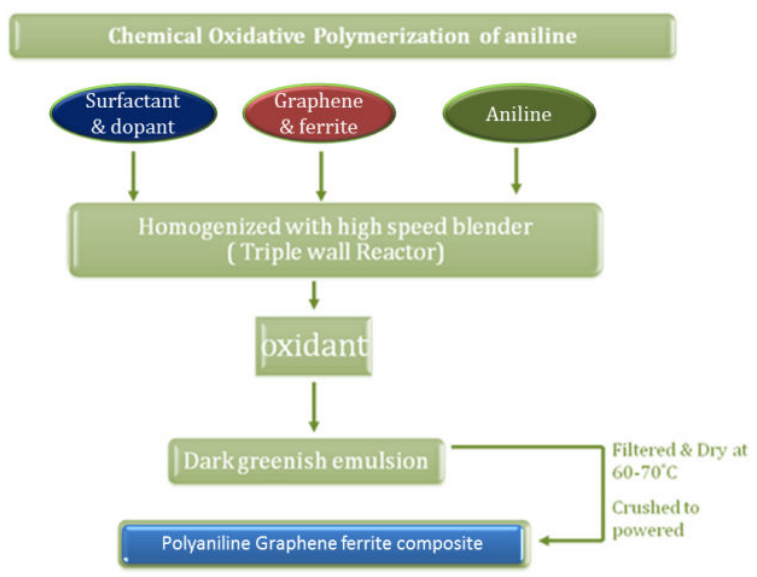

Figure 9. Pictorial representation for the formation of polyaniline nanocomposite by chemical oxidative polymerization

\subsection{Shielding Measurements}

Figure 10 shows the variation of the $\mathrm{SE}_{\mathrm{A}}$ and $\mathrm{SE}_{\mathrm{R}}$ with frequency for single layer of PG21, PGF11 and PGF12 composites in 12.4-18 GHz frequency range having thickness of $\sim 2 \mathrm{~mm}$. It has been observed that conducting composites of polyaniline with nanosize $\gamma-\mathrm{Fe}_{2} \mathrm{O}_{3}$ and GO have SE mainly attributed by absorption. The maximum shielding effectiveness due to absorption $\mathrm{SE}_{\mathrm{A}(\max )}$ has been ca. $41.6 \mathrm{~dB}$ at $16.1 \mathrm{GHz}$ for PGF12 sample whereas for PG21 and PGF11 samples the $\mathrm{SE}_{\mathrm{A}(\max )}$ has been ca. $20 \mathrm{~dB}$ at $18 \mathrm{GHz}$ and $24.8 \mathrm{~dB}$ at $13.8 \mathrm{GHz}$, respectively. For the reflection part, the $\mathrm{SE}_{\mathrm{R}(\max )}$ has been ca. $7.7 \mathrm{~dB}$ at $12.4 \mathrm{GHz}$ for PG21 sample whereas for PGF11 and PGF12 samples the $\mathrm{SE}_{\mathrm{R}(\max )}$ has been ca. 1.3 and $2 \mathrm{~dB}$ at $18 \mathrm{GHz}$, re- 
spectively. The higher values of $\mathrm{SE}_{\mathrm{A}}$ strongly suggest that the microwave absorption in the PGF nanocomposites results mainly from the absorption loss rather than the reflection loss. In addition, it is observed that SE increases with the concentration of $\gamma-\mathrm{Fe}_{2} \mathrm{O}_{3}$ in the polymer matrix. The increase in the absorption part is mainly attributed to be due to the presence of $\mathrm{GO}$ and a magnetic $\gamma-\mathrm{Fe}_{2} \mathrm{O}_{3}$ nanomaterial which increase more scattering which in turn results in more attenuation of the electromagnetic radiations. Moreover, with the change in the frequency in $12-18 \mathrm{GHz}$, the variation in the $\mathrm{SE}_{\mathrm{A}}$ value is very small, showing high bandwidth, which is commercially important for wide band absorbers. Clearly, compared to the other carbon coated magnetic nanoparticle as reported by Zhang et al. [142] ( $R_{\max }$ is ca. $32 \mathrm{~dB})$ and Tang et al. [143] ( $\mathrm{R}_{\max }$ is ca. $\left.-36 \mathrm{~dB}\right)$ these PGF composites demonstrate superior absorption properties.

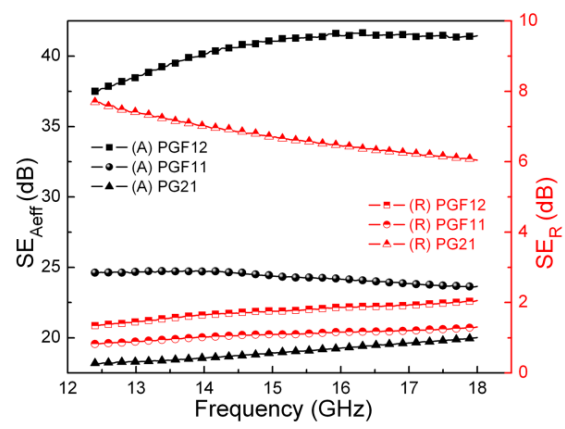

Figure 10. Dependence of shielding effectiveness $\left(S_{A} \& S E_{R}\right)$ of polyaniline composites PG21, PGF11 and PGF12 on frequency in $12.4-18 \mathrm{GHz}$

The total shielding effectiveness $\left(\mathrm{SE}_{\mathrm{T}}=\mathrm{SE}_{\mathrm{R}}+\mathrm{SE}_{\mathrm{A}}\right)$ of the respective samples has been calculated and it is observed that the PGF12 composite show maximum $\mathrm{SE}_{\mathrm{T}}$ value of $43.5 \mathrm{~dB}$ whereas total SE for PG21 and PGF11 composites is of same order i.e. $26 \mathrm{~dB}$. In PG21 composite, incorporation of $\mathrm{GO}$ in the polymer matrix increase the total $\mathrm{SE}$ to $26 \mathrm{~dB}$ in which $\sim 18$ $\mathrm{dB}$ is due to absorption and $\sim 8 \mathrm{~dB}$ is due to the reflection. With the addition of $\gamma-\mathrm{Fe}_{2} \mathrm{O}_{3}$ nanoparticles the absorption part increases to $\sim 24.5 \mathrm{~dB}$ while reflection part decreases to $1.5 \mathrm{~dB}$ and further by doubling the concentration of $\gamma-\mathrm{Fe}_{2} \mathrm{O}_{3}$ nanoparticles the absorption value enhanced to $41.6 \mathrm{~dB}$. This increase in the absorption of microwave is due to the fact that in PG21 only dielectric losses contributes to the $\mathrm{SE}_{\mathrm{A}}$ whereas in PGF11 both dielectric and magnetic losses contributes to the absorption of microwaves. The dependence of SE on complex permittivity and permeability can be expressed as [144]

$$
S E_{A}(d B)=20 \frac{d}{\delta} \log e=20 d \sqrt{\frac{\mu_{r} \omega \sigma_{A C}}{2}} \cdot \log e
$$




$$
S E_{R}(d B)=10 \log \left(\frac{\sigma_{A C}}{16 \omega \mu_{r} \varepsilon_{0}}\right)
$$

where, $d$ is the thickness of the shield, $\mu_{\mathrm{r}}$ is the magnetic permeability, $\delta$ is the skin depth, $\sigma_{A C}=\omega \varepsilon_{0} \varepsilon "$ is the frequency dependent conductivity [145], $\varepsilon^{\prime \prime}$ is imaginary part of permittivity (dielectric loss factor), $\omega$ is the angular frequency $(\omega=2 \pi \mathrm{f})$ and $\varepsilon_{0}$ is the permittivity of the free space. From equations $8 \& 9$, it is observed that with the increase in frequency, the $\mathrm{SE}_{\mathrm{A}}$ values increases while the contribution of the reflection decreases. Dependence of $\mathrm{SE}_{\mathrm{A}}$ and $\mathrm{SE}_{\mathrm{R}}$ on conductivity and permeability revel that the material having higher conductivity and magnetic permeability can achieve better absorption properties.

\subsection{Complex permittivity and permeability}

To investigate the possible mechanism and effects giving rise to improve microwave absorption, complex permittivity $\left(\varepsilon_{\mathrm{r}}=\varepsilon^{\prime}-\mathrm{j} \varepsilon^{\prime \prime}\right)$ and permeability $\left(\mu_{\mathrm{r}}=\mu^{\prime}-\mathrm{j} \mu^{\prime \prime}\right)$ of the samples have been calculated using scattering parameters $\left(S_{11} \& S_{21}\right)$ based on the theoretical calculations given in Nicholson, Ross and Weir method $[146,147]$. The dielectric performance of the material depends on ionic, electronic, orientational and space charge polarization. The contribution to the space charge polarization appears due to the heterogeneity of the material. The real $\left(\varepsilon^{\prime}\right)$ and imaginary $\left(\varepsilon^{\prime \prime}\right)$ part of complex permittivity vs. frequency has been shown in Fig. 11 (a\&b). The real part $\left(\varepsilon^{\prime}\right)$ is mainly associated with the amount of polarization occurring in the material while the imaginary part $\left(\varepsilon^{\prime \prime}\right)$ is related with the dissipation of energy. In polyaniline, strong polarization occurs due to the presence of polaron/bipolaron and other bound charges, which leads to high value of $\varepsilon^{\prime} \& \varepsilon^{\prime \prime}$. With the increase in frequency, the dipoles present in the system cannot reorient themselves along with the applied electric field as a result of this dielectric constant decreases.

The main characteristic feature of GO is that it has high dielectric constant ( $\left.\varepsilon^{\prime} \sim 32\right)$ with dominant dipolar polarization and the associated relaxation phenomenon constitutes the loss mechanism. With the addition of GO and $\gamma-\mathrm{Fe}_{2} \mathrm{O}_{3}$ in polyaniline matrix, significant increase in the imaginary part of complex permittivity has been observed. The higher values of the dielectric loss is attributed to the more interfacial polarization due to the presence of GO and $\gamma-\mathrm{Fe}_{2} \mathrm{O}_{3}$ particles which consequently leads to more shielding effectiveness due to absorption. Fig. 12 ( $a \& b$ ) shows the variation of real part and imaginary part of magnetic permeability with frequency. The magnetic permeability of all the samples decreases with the increase in frequency whereas, higher magnetic loss has been observed for higher percentage of $\gamma-\mathrm{Fe}_{2} \mathrm{O}_{3}$ in the polymer matrix. 

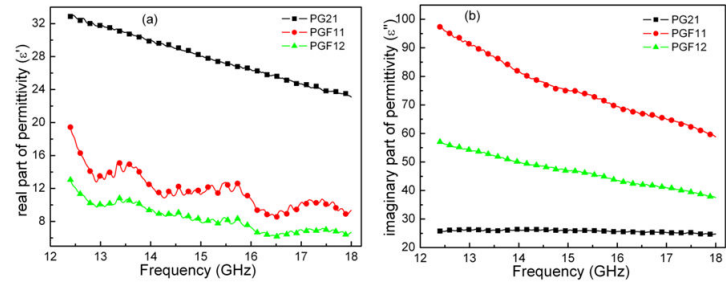

Figure 11. Behavior of (a) real and (b) imaginary part of permittivity of PG21, PGF11 and PGF12 composites as a function of frequency
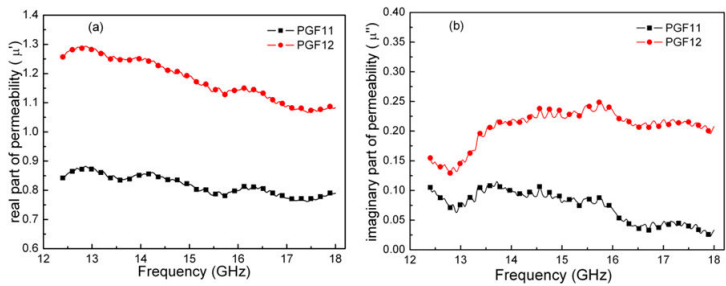

Figure 12. Variation of real and imaginary part of magnetic permeability of PGF11 and PGF12 composites as a function of frequency

The magnetic loss caused by the time lag of magnetization vector $(\mathrm{M})$ behind the magnetic field vector. The change in magnetization vector generally brought about by the rotation of magnetization and the domain wall displacement. These motions lag behind the change of the magnetic field and contribute to the magnetic loss $\left(\mu^{\prime \prime}\right)$. The rotation of domain of magnetic nanoparticles might become difficult due to the effective anisotropy (magneto-crystalline anisotropy and shape anisotropy). The surface area, number of atoms with dangling bonds and unsaturated coordination on the surface of polymer matrix are all enhanced [148-150]. These variations lead to the interface polarization and multiple scattering, which is useful for the absorption of large number of microwaves. Therefore we can conclude that, incorporation of graphene along with ferrite nanoparticles in the polyaniline matrix by in-situ emulsion polymerization.leads to increase the absorption of the electromagnetic wave to a large extent. The high value of shielding effectiveness due to absorption ( $41.6 \mathrm{~dB}$ that demonstrates $>99.99 \%$ attenuation of microwave) has been obtained because of the interfacial dipolar polarization and higher anisotropic energy due to the nano-size of the GO and $\gamma-\mathrm{Fe}_{2} \mathrm{O}_{3}$. The dependence of $\mathrm{SE}_{\mathrm{A}}$ on magnetic permeability and ac conductivity shows that better absorption value can be obtained for a material having higher conductivity and magnetization.

In another article, Basavaraja et al [151] has synthesized polyaniline-gold-GO nanocomposite by an in situ polymerization and reports the microwave absorption property in the $2-12$ $\mathrm{GHz}$ frequency range. They found electromagnetic interference shielding effectiveness of polyaniline gold nanocomposite (PANI-GNP) has been enhanced due to the inclusion of 
$25 \%$ by weight GO in the polyaniline matrix. In Figure 13a, FT-IR spectra of GO, PANIGNP, and PANI-GNP-GO has shown which clearly shows that some small deviations from the characteristic band of polyaniline that may be attributed some molecular interaction between GO with polyaniline ring has taken place this can be supported by UV-Vis spectra as shown in figure 14b. The spectrum for PANI-GNP shows three sharp absorption bands at around 320,415 , and $550 \mathrm{~nm}$ attributed to the $\pi-\pi^{*}$ transition of the benzenoid rings, and the polaron/bipolaron transition. The presence of GNPs is shown by the absorption peak at $520-530 \mathrm{~nm}$. The peak at $550 \mathrm{~nm}$ indicates the presence of GNPs in PANI-GNP and their conjugation with PANI. The spectrum for PANI-GNP-GO shows all three absorption bands with slightly larger area as compared to that of PANI-GNP and red shift has taken place. However the GO peak in PANI-GNP-GO appeared to merged with the $\pi-\pi^{*}$ transition of the benzenoid rings. Figure 14c shows the SEM images Here the lump- and fiber-like structures of PANI-GNP disappeared after incorporation of GO into the matrix while the Figure 13d shows the TEM images for PANI-GNP and PANI-GNP-GO. In PANI-GNP, spherical GNPs covered by PANI polymers formed nano-capsules. These particles had a diameter between 25 and $45 \mathrm{~nm}$. After the incorporation of GO in PANI-GNP, the surface morphology of PANI-GNP- GO changed. The spherical PANI-GNP particles disappeared and new pellet/flake-like structures were formed.

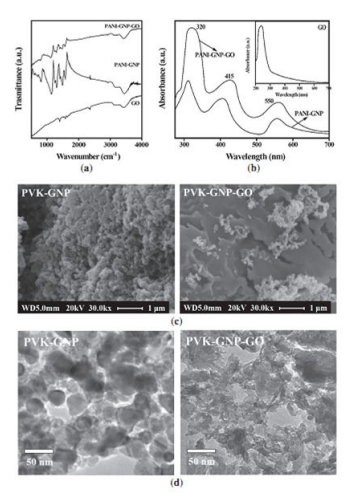

Figure 13. a) FT-IR spectra of GO, PANI-GNP, and PANI-GNP-GO, (b) UV-Vis spectra of GO, PANI-GNP, and PANI-GNPGO, (c) SEM images of PANI-GNP and PANI-GNP-GO, (d) TEM images of PANI-GNP and PANI-GNP-GO (Reprinted from ref 151 Copyright (2011), with permission from Elsevier)

The variation of the electromagnetic interference (EMI) shielding effectiveness (SE) as a function of frequency measured in the 2.0-12.0 GHz for GO, PANI-GNP, and PANI-GNPGO films are shown in figure 14a Here GO exhibited lower values of SE, The SE values observed for GO and PANI-GNP in this frequency range were 20-33 and 45-69 dB, respectively. The higher values in the PANI-GNP are mainly attributed to the presence of GNPs. The highest values of SE have been observed in the PANIGNP- GO composite. The observed SE values for PANI-GNP-GO were within 90-120 dB. This range of values is very 
high compared with other carbon-based materials [152]. The EMI-SE data suggest that the electrochemical responses of PANI-GNP have been enhanced due to the inclusion of GO. Figure $14 \mathrm{~b}$ shows the SE values variation with the thickness at $9.0 \mathrm{GHz}$. The SE values increase with increasing thickness of the sheets. This probably would overcome the poor cycling life, processability and solubility of the homo-polymer.
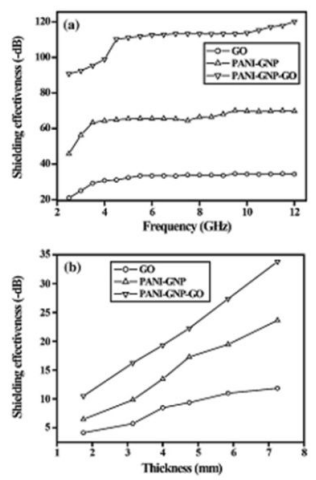

Figure 14. a) EMI-SE values as a function of frequency measured at 2.0-12.0 GHz. (b) EMI-SE values as a function of sheet thickness at $9.0 \mathrm{GHz}$ for GO, PANI-GNP, and PANI-GNP-GO. (Reprinted from ref 151 Copyright (2011), with permission from Elsevier)

\section{Conclusion}

Although most of the research progress has been made in understanding the structure, processing, and properties of GO/RGO-based compound, there is significantly more to be explored and exploited given the highly versatile properties of the material. GO provides an exciting platform to study engineering, physics, chemistry, and materials science of unique 2D systems as well as offers a route towards realizing conducting polymer graphene composite. Continued involvement of researchers from all disciplines should further uncover the potential of GO/RGO polymer to processible and highly user friendly end product The enhancement in the microwave shielding and absorption properties of the polyaniline nanocomposite has been achieved by the incorporation of GO \& RGO along with the magnetic filler in the polyaniline matrix. Now there is a need to form Graphene polymer composite paint that can be easily coat over the electronic encloser. Therefore, from the present studies, it can be concluded that the incorporation of magnetic and dielectric fillers in the polymer matrix lead to better absorbing material which make them futuristic radar absorbing material.

In spite of these interesting developments, a lot remains to be done with regard to both fundamental understanding and the much needed improvement of the method of the designing of electromagnetic shielding materials to operate at higher frequencies for their application. 


\section{Author details}

Kuldeep Singh ${ }^{1}$, Anil Ohlan ${ }^{2}$ and S.K. Dhawan ${ }^{1 *}$

*Address all correspondence to: skdhawan@mail.nplindia.ernet.in

1 Polymeric \& Soft Material Section, National Physical Laboratory (CSIR), New Delhi -110 012, India

2 Department of Physics, Maharshi Dayanand University Rohtak - 124001, India

\section{References}

[1] Lincoln Vogel, F. (1977). The electrical conductivity of graphite intercalated with superacid fluorides: experiments with antimony pentafluoride. Journal of Materials Science, 12(5), 982-986.

[2] Kroto, H. W., Heath, J. R., O'Brien, S. C., Curl, R. F., \& Smalley, R. E. (1985). C60: Buckminsterfullerene. Nature, 318(6042), 162-163.

[3] Iijima, S. (1991). Helical microtubules of graphitic carbon. Nature, 354(6348), 56-58.

[4] Novoselov, K.S., Geim, A.K., Morozov, S.V., Jiang, D., Zhang, Y., Dubonos, S.V., Grigorieva, I.V., \& Firsov, A.A. (2004). Electric Field Effect in Atomically Thin Carbon Films. Science, 306(5696), 666-669.

[5] Novoselov, A. K., Geim, S. V., Morozov, D., Jiang, M. I., Katsnelson, I.V., Grigorieva, S. V., Dubonos, S. V., \& Firsov, A. A. (2005). Two-dimensional gas of massless Dirac fermions in graphene. Nature, 438(7065), 197-200.

[6] Zhang, Y., Tan, Y.W., Stormer, H.L., \& Kim, P. (2005). Experimental observation of the quantum Hall effect and Berry's phase in graphene. Nature, 438(7065), 201-204.

[7] Balandin, A. A., Ghosh, S., Bao, W., Calizo, I., Teweldebrhan, D., Miao, F., \& Lau, C. N. (2008). Superior Thermal Conductivity of Single-Layer Graphene. Nano Letters, 8(3), 902-907.

[8] Nair, R. R., Blake, P., Grigorenko, A. N., Novoselov, K. S., Booth, T. J., Stauber, T., Peres, N. M. R., \& Geim, A. K. (2008). Fine Structure Constant Defines Visual Transparency of Graphene. Science, 320(5881), 1308.

[9] Li, X., Wang, X., Zhang, L., Lee, S., \& Dai, H. (2008). Chemically Derived, Ultrasmooth Graphene Nanoribbon Semiconductors. Science, 319(5867), 1229-1232.

[10] Ritter, K. A., \& Lyding, J. W. (2009). The influence of edge structure on the electronic properties of graphene quantum dots and nanoribbons. Nat Mater, 8(3), 235-242. 
[11] Cai, J., Ruffieux, P., Jaafar, R., Bieri, M., Braun, T., Blankenburg, S., Muoth, M., Seitsonen, A. P., Saleh, M., Feng, X., Mullen, K., \& Fasel, R. (2010). Atomically precise bottom-up fabrication of graphene nanoribbons. Nature, 466(7305), 470-473.

[12] Ansari, S., \& Giannelis, E. P. (2009). Functionalized graphene sheet-Poly(vinylidene fluoride) conductive nanocomposites. Journal of Polymer Science Part B: Polymer Physics, 47(9), 888-897.

[13] Ramanathan, T., Abdala, A. A., Stankovich, S., Dikin, D. A., Herrera, Alonso. M., Piner, R. D., Adamson, D. H., Schniepp, H. C., Chen, X., Ruoff, R. S., Nguyen, S. T., Aksay, I. A., Prud'Homme, R. K., \& Brinson, L. C. (2008). Functionalized graphene sheets for polymer nanocomposites. Nat Nano, 3(6), 327-331.

[14] Stankovich, S., Dikin, D. A., Dommett, G. H. B., Kohlhaas, K. M., Zimney, E. J., Stach, E. A., Piner, R. D., Nguyen, S. T., \& Ruoff, R. S. (2006). Graphene-based composite materials. Nature, 442(7100), 282-286.

[15] Fan, H., Wang, L., Zhao, K., Li, N., Shi, Z., Ge, Z., \& Jin, Z. (2010). Fabrication, Mechanical Properties, and Biocompatibility of Graphene-Reinforced Chitosan Composites. Biomacromolecules, 11(9), 2345-2351.

[16] Zhang, K., Zhang, L. L., Zhao, X. S., \& Wu, J. (2010). Graphene/Polyaniline Nanofiber Composites as Supercapacitor Electrodes. Chemistry of Materials. ; , 22(4), 1392-1401.

[17] Zhao, X., Zhang, Q., Chen, D., \& Lu, P. (2010). Enhanced Mechanical Properties of Graphene-Based Poly(vinyl alcohol) Composites. Macromolecules, 43(5), 2357-2363.

[18] Kuila, T., Bose, S., Hong, C. E., Uddin, M. E., Khanra, P., Kim, N. H., \& Lee, J. H. (2011). Preparation of functionalized graphene/linear low density polyethylene composites by a solution mixing method. Carbon, 49(3), 1033-1037.

[19] Wu, J., Becerril, H. A., Bao, Z., Liu, Z., Chen, Y., \& Peumans, P. (2008). Organic solar cells with solution-processed graphene transparent electrodes. Applied Physics Letters, 92(26), 263-302.

[20] Huang, J., Wang, X., de Mello, A. J., de Mello, J. C., \& Bradley, D. D. C. (2007). Efficient flexible polymer light emitting diodes with conducting polymer anodes. Journal of Materials Chemistry, 17(33), 3551-3554.

[21] Park, H., Rowehl, J. A., Kim, K. K., Bulovic, V., \& Kong, J. (2010). Doped graphene electrodes for organic solar cells. Nanotechnology, 21(505204).

[22] Li, D., Muller, M. B., Gilje, S., Kaner, R. B., \& Wallace, G. G. (2008). Processable aqueous dispersions of graphene nanosheets. Nat Nano, 3(2), 101-105.

[23] Shan, C., Yang, H., Han, D., Zhang, Q., Ivaska, A., \& Niu, L. (2009). Water-Soluble Graphene Covalently Functionalized by Biocompatible Poly-l-lysine. Langmuir, 25(20), 12030-12033.

[24] Si, Y., \& Samulski, E. T. (2008). Synthesis of Water Soluble Graphene. Nano Letters, 8(6), 1679-1682. 
[25] Green, A. A., \& Hersam, M. C. (2009). Solution Phase Production of Graphene with Controlled Thickness via Density Differentiation. Nano Letters, 9(12), 4031-4036.

[26] Chen, G., Wu, D., Weng, W., \& Wu, C. (2003). Exfoliation of graphite flake and its nanocomposites. Carbon, 41(3), 619-62.

[27] Pötschke, P., Abdel, Goad. M., Pegel, S., Jehnichen, D., Mark, J. E., Zhou, D., \& Heinrich, G. (2009). Comparisons Among Electrical and Rheological Properties of MeltMixed Composites Containing Various Carbon Nanostructures. Journal of Macromolecular Science, 47(1), 12-19.

[28] Yasmin, A., Luo, J. J., \& Daniel, I. M. (2006). Processing of expanded graphite reinforced polymer nanocomposites. Composites Science and Technology, 66(9), 1182-1189.

[29] Jang, B., \& Zhamu, A. (2008). Processing of nanographene platelets (NGPs) and NGP nanocomposites: a review. Journal of Materials Science, 43(15), 5092-5101.

[30] Li, X., Zhang, G., Bai, X., Sun, X., Wang, X., Wang, E., \& Dai, H. (2008). Highly conducting graphene sheets and Langmuir-Blodgett films. Nat Nano, 3(9), 538-542.

[31] Blake, P., Brimicombe, P. D., Nair, R. R., Booth, T. J., Jiang, D., Schedin, F., Ponomarenko, L. A., Morozov, S. V., Gleeson, H. F., Hill, E. W., Geim, A. K., \& Novoselov, K. S. (2008). Graphene-Based Liquid Crystal Device. Nano Letters, 8(6), 1704-1708.

[32] Hernandez, Y., Nicolosi, V., Lotya, M., Blighe, F. M., Sun, Z., De , S., Mc Govern, I. T., Holland, B., Byrne, M., Gun, Ko. Y. K., Boland, J. J., Niraj, P., Duesberg, G., Krishnamurthy, S., Goodhue, R., Hutchison, J., Scardaci, V., Ferrari, A. C., \& Coleman, J. N. (2008). High-yield production of graphene by liquid-phase exfoliation of graphite. Nat Nano, 3(9), 563-568.

[33] Lotya, M., Hernandez, Y., King, P. J., Smith, R. J., Nicolosi, V., Karlsson, L. S., Blighe, F. M., De , S., Wang, Z., Mc Govern, I. T., Duesberg, G. S., (2009, , \& Coleman, J. N. Liquid Phase Production of Graphene by Exfoliation of Graphite in Surfactant/Water Solutions. Journal of the American Chemical Society, 131(10), 3611-3620.

[34] Li, X., Cai, W., An, J., Kim, S., Nah, J., Yang, D., Piner, R., Velamakanni, A., Jung, I., Tutuc, E., Banerjee, S. K., Colombo, L., \& Ruoff, R. S. (2009). Large-Area Synthesis of High-Quality and Uniform Graphene Films on Copper Foils. Science, 324(5932), 1312-1314.

[35] Malesevic, A., Vitchev, R., Schouteden, K., Volodin, A., Zhang, L., Tendeloo, G. V., Vanhulsel, A., \& Haesendonck, C. V. (2008). Synthesis of few-layer graphene via microwave plasma-enhanced chemical vapour deposition. Nanotechnology, 19(305604).

[36] Dervishi, E., Li, Z., Watanabe, F., Biswas, A., Xu, Y., Biris, A. R., Saini, V., \& Biris, A. S. (2009). Large-scale graphene production by RF-cCVD method. Chemical Communications, 27-4061. 
[37] Reina, A., Jia, X., Ho, J., Nezich, D., Son, H., Bulovic, V., Dresselhaus, M. S., \& Kong, J. (2008). Large Area, Few-Layer Graphene Films on Arbitrary Substrates by Chemical Vapor Deposition. Nano Letters, 9(1), 30-35.

[38] Sutter, P. W., Flege, J. I., \& Sutter, E. A. (2008). Epitaxial graphene on ruthenium. Nat Mater, 7(5), 406-411.

[39] Srivastava, A., Galande, C., Ci, L., Song, L., Rai, C., Jariwala, D., Kelly, K. F., \& Ajayan, P. M. (2010). Novel Liquid Precursor-Based Facile Synthesis of Large-Area Continuous, Single, and Few-Layer Graphene Films. Chemistry of Materials, 22(11), 3457-3461.

[40] Nandamuri, G., Roumimov, S., \& Solanki, R. (2010). Chemical vapor deposition of graphene films. Nanotechnology, 21-145604.

[41] Bae, S., Kim, H., Lee, Y., Xu, X., Park, J. S., Zheng, Y., Balakrishnan, J., Lei, T., Ri, Kim. H., Song, Y. I., Kim, Y. J., Kim, K. S., Ozyilmaz, B., Ahn, J. H., Hong, B. H., \& Iijima, S. (2010). Roll-to-roll production of 30-inch graphene films for transparent electrodes. Nat Nano, 5(8), 574-578.

[42] Shivaraman, S., Barton, R. A., Yu, X., Alden, J., Herman, L., Chandrashekhar, M. V. S., Park, J., Mc Euen, P. L., Parpia, J. M., Craighead, H. G., \& Spencer, M. G. (2009). Free-Standing Epitaxial Graphene. Nano Letters, 9(9), 3100-3105.

[43] Aristov, V. Y., Urbanik, G., Kummer, K., Vyalikh, D. V., Molodtsova, O. V., Preobrajenski, A. B., Zakharov, A. A., Hess, C., Ha®nke, T., Bu®chner, B., Vobornik, I., Fujii, J., Panaccione, G., Ossipyan, Y. A., \& Knupfer, M. (2010). Graphene Synthesis on Cubic SiC/Si Wafers. Perspectives for Mass Production of Graphene-Based Electronic Devices. Nano Letters, 10(3), 992-995.

[44] Emtsev, K. V., Bostwick, A., Horn, K., Jobst, J., Kellogg, G. L., Ley, L., Mc Chesney, J. L., Ohta, T., Reshanov, S. A., Rohrl, J., Rotenberg, E., Schmid, A. K., Waldmann, D., Weber, H. B., \& Seyller, T. (2009). Towards wafer-size graphene layers by atmospheric pressure graphitization of silicon carbide. Nat Mater, 8(3), 203-207.

[45] Deng, D., Pan, X., Zhang, H., Fu, Q., Tan, D., \& Bao, X. (2010). Freestanding Graphene by Thermal Splitting of Silicon Carbide Granules. Advanced Materials, 22(19), 2168-2171.

[46] Stankovich, S., Dikin, D. A., Dommett, G. H. B., Kohlhaas, K. M., Zimney, E. J., Stach, E. A., Piner, R. D., Nguyen, S. T., \& Ruoff, R. S. (2006). Graphene-based composite materials. Nature, 442(7100), 282-286.

[47] Verdejo, R., Bernal, M. M., Romasanta, L. J., \& Lopez, Manchado. M. A. (2011). Graphene filled polymer nanocomposites. Journal of Materials Chemistry, 21(10), 3301-3310.

[48] Gilje, S., Han, S., Wang, M., Wang, K. L., \& Kaner, R. B. (2007). A Chemical Route to Graphene for Device Applications. Nano Letters, 7(11), 3394-3398. 
[49] Brodie, B. C. (1859). On the Atomic Weight of Graphite. Philosophical Transactions of the Royal Society of London.

[50] Staudenmaier, L. (1898). Verfahren zur Darstellung der Graphitsäure. Berichte der deutschen chemischen Gesellschaft, 31(2), 1481-1487.

[51] Hummers, W. S., \& Offeman, R. E. (1958). Preparation of Graphitic Oxide. Journal of the American Chemical Society, 80(6), 1339.

[52] Marcano, D. C., Kosynkin, D. V., Berlin, J. M., Sinitskii, A., Sun, Z., Slesarev, A., Alemany, L. B., Lu, W., \& Tour, J. M. (2010). Improved Synthesis of Graphene Oxide. ACS Nano, 4(8), 4806-4814.

[53] Shen, J., Hu, Y., Shi, M., Lu, X., Qin, C., Li, C., \& Ye, M. (2009). Fast and Facile Preparation of Graphene Oxide and Reduced Graphene Oxide Nanoplatelets. Chemistry of Materials, 21(15), 3514-3520.

[54] Paredes, J. I., Villar, Rodil. S., Martínez, Alonso. A., \& Tascón, J. M. D. (2008). Graphene Oxide Dispersions in Organic Solvents. Langmuir, 24(19), 10560-10564.

[55] Pham, V. H., Cuong, T. V., Dang, T. T., Hur, S. H., Kong, B. S., Kim, E. J., Shin, E. W., \& Chung, J. S. (2011). Superior conductive polystyrene chemically converted graphene nanocomposite. Journal of Materials Chemistry, 21(30), 11312-11316.

[56] Gilje, S., Han, S., Wang, M., Wang, K. L., \& Kaner, R. B. (2007). A Chemical Route to Graphene for Device Applications. Nano Letters, 7(11), 3394-3398.

[57] Eda, G., Fanchini, G., \& Chhowalla, M. (2008). Large-area ultrathin films of reduced graphene oxide as a transparent and flexible electronic material. Nat Nano, 3(5), 270-274.

[58] Eda, G., \& Chhowalla, M. (2010). Adv. Mater., 22(2392).

[59] Stankovich, S., Dikin, D. A., Dommett, G. H. B., Kohlhaas, K. M., Zimney, E. J., Stach, E. A., Piner, R. D., Nguyen, S. T., \& Ruoff, R. S. (2006). Graphene-based composite materials. Nature, 442(7100), 282-286.

[60] Ramanathan, T., Abdala, A. A., Stankovich, S., Dikin, D. A., Herrera, Alonso. M., Piner, R. D., Adamson, D. H., Schniepp, H. C., Chen, X., Ruoff, R. S., Nguyen, S. T., Aksay, I. A., Prud, Homme. R. K., \& Brinson, L. C. (2008). Functionalized graphene sheets for polymer nanocomposites. Nat Nano, 3(6), 327-331.

[61] Kim, H., Abdala, A. A., \& Macosko, C. W. (2010). Graphene/Polymer. Nanocomposites. Macromolecules, 43(16), 6515-6530.

[62] Pham, V. H., Cuong, T. V., Dang, T. T., Hur, S. H., Kong, B. S., Kim, E. J., Shin, E. W., \& Chung, J. S. (2011). Superior conductive polystyrene chemically converted graphene nanocomposite. Journal of Materials Chemistry, 21(30), 11312-11316.

[63] Stoller, M. D., Park, S., Zhu, Y., An, J., \& Ruoff, R. S. (2008). Graphene-Based Ultracapacitors. Nano Letters, 8(10), 3498-3502. 
[64] Kamat, P. V. (2011). Graphene-Based Nanoassemblies for Energy Conversion. The Journal of Physical Chemistry. Letters, 2(3), 242-251.

[65] Shao, Y., Wang, J., Wu, H., Liu, J., Aksay, I. A., \& Lin, Y. (2010). Graphene Based Electrochemical Sensors and Biosensors:. A Review. Electroanalysis, 22(10), 1027-1036.

[66] Kaiser, A. B. (2001). Electronic transport properties of conducting polymers and carbon nanotubes. Rep Prog Phys., 64(1), 1-49.

[67] Kopelevich, Y., \& Esquin, P. (2007). Graphene physics in graphite. Adv Mater., 19(24), 455-9.

[68] Stankovich, S., Dikin, D. A., Piner, R. D., Kohlhaas, K. A., Kleinhammes, A., Jia, Y., Wu, Y., Nguyen, S. T., \& Ruoff, R. S. (2007). Synthesis of graphene-based nanosheets via chemical reduction of exfoliated graphite oxide. Carbon, 45(7), 1558-1565.

[69] Li, D., Muller, M. B., Gilje, S., Kaner, R. B., Wallace, G., \& , G. (2008). Processable aqueous dispersions of graphene nanosheets. Nat Nano, 3(2), 101-105.

[70] Pham, V. H., Cuong, T. V., Nguyen, Phan. T. D., Pham, H. D., Kim, E. J., Hur, S. H., Shin, E. W., Kim, S., \& Chung, J. S. (2010). One-step synthesis of superior dispersion of chemically converted graphene in organic solvents. Chemical Communications, 46(24), 4375-4377.

[71] Eda, G., Fanchini, G., \& Chhowalla, M. (2008). Large-area ultrathin films of reduced graphene oxide as a transparent and flexible electronic material. Nat Nano, 3(5), 270-274.

[72] Park, S., An, J., Jung, I., Piner, R.D., An, S.J., Li, X., Velamakanni, A., \& Ruoff, R.S. ((2009). ).Colloidal Suspensions of Highly Reduced Graphene Oxide in a Wide Variety of Organic Solvents. Nano Letters , 9(4), 1593-1597.

[73] Villar, P., Rodil, S., Paredes, J. I., Martinez, Alonso. A., \& Tascon, J. M. D. (2009). Preparation of graphene dispersions and graphene-polymer composites in organic media. Journal of Materials Chemistry, 19(22), 3591-3593.

[74] Shin, H. J., Kim, K. K., Benayad, A., Yoon, S. M., Park, H. K., , I., Jung, S., Jin, M. H., Jeong, H. K., Kim, J. M., Choi, J. Y., \& Lee, Y. H. (2009). Adv. Funct. Mater., 19(1987).

[75] Moon, I. K., Lee, J., Ruoff, R. S., \& Lee, H. (2010). Reduced graphene oxide by chemical graphitization. Nat Commun, 1(73).

[76] Pham, H. D., Pham, V. H., Cuong, T. V., Nguyen, Phan. T. D., Chung, J. S., Shin, E. W., \& Kim, S. (2011). Synthesis of the chemically converted graphene xerogel with superior electrical conductivity. Chemical Communications, 47(34), 9672-9674.

[77] Chen, W., Yan, L., \& Bangal, P. R. (2010). Chemical Reduction of Graphene Oxide to Graphene by Sulfur-Containing Compounds. The Journal of Physical Chemistry, 114(47), 19885-19890. 
[78] Zhang, J., Yang, H., Shen, G., Cheng, P., Zhang, J., \& Guo, S. (2010). Reduction of graphene oxide vial-ascorbic acid. Chemical Communications, 46(7), 1112-1114.

[79] Gao, J., Liu, F., Liu, Y., Ma, N., Wang, Z., \& Zhang, X. (2010). Environment-Friendly Method To Produce Graphene That Employs Vitamin C and Amino Acid. Chemistry of Materials, 22(7), 2213-2218.

[80] Hontoria, ]., Lucas, C., López Peinado, A. J., López, González. J. D., Rojas, Cervantes. M. L., \& Martín-Aranda, R. M. (1995). Study of oxygen-containing groups in a series of graphite oxides: Physical and chemical characterization. Carbon, 33(11), 1585-1592.

[81] Jeong, H. K., Lee, Y. P., Lahaye, R. J. W. E., Park, M. H., An, K. H., Kim, I. J., et al. (2008). Evidence of graphitic ab stacking order of graphite oxides. J Am Chem Soc., 130(4), 136-2.

[82] Gao, W., Alema, L.B., Ci, L., \& Ajayan, P. M. (2009). New insights into the structure and reduction of graphite oxide. Nat Chem., 1(5), 403-408.

[83] Schniepp, H. C., Li, J. L., Mc Allister, M. J., Sai, H., Herrera, Alonso. M., Adamson, D. H., Prud'homme, R. K., Car, R., Saville, D. A., \& Aksay, I. A. (2006). Functionalized Single Graphene Sheets Derived from Splitting Graphite Oxide. The Journal of Physical Chemistry B, 110(17), 8535-8539.

[84] Wu, Z. S., Ren, W., Gao, L., Liu, B., Jia, C., \& Cheng, H. M. (2009). Synthesis of highquality graphene with a pre-determined number of layers. Carbon, 47(2), 493-499.

[85] Kudin, K. N., Ozbas, B., Schniepp, H. C., Prudhomme, R. K., Aksay, I. A., \& Car, R. (2007). Raman Spectra of Graphite Oxide and Functionalized Graphene Sheets. Nano Letters, 8(1), 36-41.

[86] Zhao, J., Pei, S., Ren, W., Gao, L., \& Cheng, H. M. (2010). Efficient Preparation of Large-Area Graphene Oxide Sheets for Transparent Conductive Films. ACS Nano, $4(9), 5245-5252$.

[87] Becerril, H. A., Mao, J., Liu, Z., Stolten, berg. R. M., Bao, Z., \& Chen, Y. (2008). Evaluation of Solution-Processed Reduced Graphene Oxide Films as Transparent Conductors. ACS Nano, 2(3), 463-470.

[88] Wang, X., Zhi, L., \& Mullen, K. (2007). Transparent, Conductive Graphene Electrodes for Dye-Sensitized Solar Cells. Nano Letters, 8(1), 323-327.

[89] Li, X., Wang, H., Robinson, J. T., Sanchez, H., Diankov, G., \& Dai, H. (2009). Simultaneous nitrogen doping and reduction of graphene oxide. J Am Chem Soc., 131(43), 15939-15944.

[90] Stankovich, S., Dikin, D. A., Piner, R. D., \& Kohlhaas, K. A. (2007). Kleinhammes A, Jia Y, Wu Y, Nguyen ST, Ruoff RS. Synthesis of graphene-based nanosheets via chemical reduction of exfoliated graphite oxide. Carbon, 45(7), 1558-1565.

[91] Li, D., Muller, M. B., Gilje, S., \& Kaner, R. B. (2008). Wallace GG. Processable aqueous dispersions of graphene nanosheets. Nat Nano, 3(2), 101-105. 
[92] Tung, V. C., Allen, M. J., Yang, Y., \& Kaner, R. B. (2009). High-throughput solution processing of large-scale graphene. Nat. Nano, 4(1), 25-29.

[93] Park, S., An, J., Jung, I., Piner, R. D., An, S. J., Li, X., Velamakanni, A., \& Ruoff, R. S. (2009). Colloidal Suspensions of Highly Reduced Graphene Oxide in a Wide Variety of Organic Solvents. Nano Letters, 9(4), 1593-1597.

[94] Mc Allister, M. J., Li, J. L., Adamson, D. H., Schniepp, H. C., Abdala, A. A., Liu, J., Herrera-Alonso, M., Milius, D. L., Car, R., \& Prud'homme, R. K. (2007). Aksay IA.Single Sheet Functionalized Graphene by Oxidation and Thermal Expansion of Graphite. Chemistry of Materials .., 19(18), 4396-4404.

[95] Nethravathi, C., \& Rajamathi, M. (2008). Chemically modified graphene sheets produced by the solvothermal reduction of colloidal dispersions of graphite oxide. Carbon, 46(14), 1994-1998.

[96] Wang, H., Robinson, J. T., Li, X., \& Dai, H. (2009). Solvothermal Reduction of Chemically Exfoliated Graphene Sheets. Journal of the American Chemical Society, 131(29), 9910-9911.

[97] Zhou, Y., Bao, Q., Tang, L., Zhong, A. L., , Y., \& Loh, K. P. (2009). Hydrothermal Dehydration for the "Green" Reduction of Exfoliated Graphene Oxide to Graphene and Demonstration of Tunable Optical Limiting Properties. Chemistry of Materials, 21(13), 2950-2956.

[98] Zhu, Y., Stoller, M. D., Cai, W., Velamakanni, A., Piner, R. D., Chen, D., \& Ruoff, R. S. (2010). Exfoliation of Graphite Oxide in Propylene Carbonate and Thermal Reduction of the Resulting Graphene Oxide Platelets. ACS Nano, 4(2), 1227-1233.

[99] Ramesha, G. K., \& Sampath, S. (2009). Electrochemical Reduction of Oriented Graphene Oxide Films: An in Situ Raman Spectroelectrochemical Study. The Journal of Physical Chemistry, 113(19), 7985-7989.

[100] Pham, V. H., Cuong, T. V., Hur, S. H., Oh, E., Kim, E. J., Shin, E. W., \& Chung, J. S. (2011). Chemical functionalization of graphene sheets by solvothermal reduction of a graphene oxide suspension in N-methyl-2-pyrrolidone. Journal of Materials Chemistry;, 21(10), 3371-3377.

[101] Dubin, S., Gilje, S., Wang, K., Tung, V. C., Cha, K., Hall, A. S., Farrar, J., Varshneya, R., Yang, Y., \& Kaner, R. B. (2010). A one-step, solvothermal reduction method for producing reduced graphene oxide dispersions in organic solvents. ACS Nano, 4(7), 3845-3852.

[102] Dang, T. T., Pham, V. H., Hur, S. H., Kim, E. J., Kong, B. S., \& Chung, J. S. (2012). Superior dispersion of highly reduced graphene oxide in $\mathrm{N}, \mathrm{N}$-dimethylformamide. Journal of Colloid and Interface Science, 376(1), 91-96.

[103] Shimizu, F., Mizoguchi, K., Masubuchi, S., \& Kume, K. (1995). Metallic temperature dependence of resistivity in heavily doped polyacetylene by NMR. Synthetic Metals, 69(1-3), 43-44. 
[104] Roncali, J. (1992). Conjugated poly(thiophenes): synthesis, functionalization, and applications. Chemical Reviews, 92(4), 711-738.

[105] Higashika, S., Kimura, K., Matsuo, Y., \& Sugie, Y. (1999). Synthesis of polyaniline-intercalated graphite oxide. Carbon, 37(2), 354-356.

[106] Wang, P., Li, D. W., Zhao, J., Ren, W., Chen, Z. G., Tan, J., Wu, Z. S., Gentle, I., Lu, G. Q., \& Cheng, H. M. (2009). Fabrication of Graphene/Polyaniline Composite Paper via In Situ Anodic Electropolymerization for High-Performance Flexible Electrode. ACS Nano, 3(7), 1745-1752.

[107] Wang, H., Hao, Q., Yang, X., Lu, L., \& Wang, X. (2009). Graphene oxide doped polyaniline for supercapacitors. Electrochemistry Communications, 11(6), 1158-1161.

[108] Wang, H., Hao, Q., Yang, X., Lu, L., \& Wang, X. (2010). Effect of Graphene Oxide on the Properties of Its Composite with Polyaniline. ACS Applied Materials E Interfaces, 2(3), 821-828.

[109] Yan, J., Wei, T., Shao, B., Fan, Z., Qian, W., Zhang, M., \& Wei, F. (2010). Preparation of a graphene nanosheet/polyaniline composite with high specific capacitance. Carbon, 48(2), 487-493.

[110] Yang, N., Zhai, J., Wan, M., Wang, D., \& Jiang, L. (2010). Layered nanostructures of polyaniline with graphene oxide as the dopant and template. Synthetic Metals, 160(15-16)), 1617, 1622.

[111] Zhang, K., Zhang, L. L., Zhao, X. S., \& Wu, J. (2010). Graphene/Polyaniline Nanofiber Composites as Supercapacitor Electrodes. Chemistry of Materials, 22(4), 1392-1401.

[112] Bissessur, R., Liu, P. K. Y., \& Scully, S. F. (2006). Intercalation of polypyrrole into graphite oxide. Synthetic Metals, 156(16-17), 1023-102.

[113] Liu, Q., Liu, Z., Zhang, X., Yang, L., Zhang, N., Pan, G., Yin, S., Chen, Y., \& Wei, J. (2009). Polymer Photovoltaic Cells Based on Solution-Processable Graphene and 3HT. Advanced functional material, 19, 894-904.

[114] Choi, K. S., Liu, F., Choi, J. S., \& Seo, T. S. (2010). Fabrication of Free-Standing Multilayered Graphene and Poly(3,4-ethylenedioxythiophene) Composite Films with Enhanced Conductive and Mechanical Properties. Langmuir, 26(15), 12902-12908.

[115] Murugan, A. V., Muraliganth, T., \& Manthiram, A. (2009). Rapid, Facile MicrowaveSolvothermal Synthesis of Graphene Nanosheets and Their Polyaniline Nanocomposites for Energy Strorage. Chemistry of Materials, 21(21), 5004-5006.

[116] Yan, J., Wei, T., Shao, B., Fan, Z., Qian, W., Zhang, M., \& Wei, F. (2010). Preparation of a graphene nanosheet/polyaniline composite with high specific capacitance. Carbon, 48(2), 487-493.

[117] Zhang, K., Zhang, L. L., Zhao, X. S., \& Wu, J. (2010). Graphene/Polyaniline Nanofiber Composites as Supercapacitor Electrodes. Chemistry of Materials, 22(4), 1392-1401. 
[118] Wu, Q., Xu, Y., Yao, Z., Liu, A., \& Shi, G. (2010). Supercapacitors Based on Flexible Graphene/Polyaniline. Nanofiber Composite Films, ACS Nano, 4(4), 1963-1970.

[119] Xu, Y., Wang, Y., Liang, J., Huang, Y., Ma, Y., Wan, X., \& Chen, Y. (2009). A hybrid material of graphene and poly (3,4-ethyldioxythiophene) with high conductivity, flexibility, and transparency. Nano Research, 2(4), 343-348.

[120] Bai, H., Xu, Y., Zhao, L., Li, C., \& Shi, G. (2009). Non-covalent functionalization of graphene sheets by sulfonated polyaniline. Chemical Communications, 13-1667.

[121] Yang, H., Zhang, Q., Shan, C., Li, F., Han, D., \& Niu, L. (2010). Stable, Conductive Supramolecular Composite of Graphene Sheets with Conjugated Polyelectrolyte. Langmuir, 26(9), 6708-6712.

[122] Yang, H., Zhang, Q., Shan, C., Li, F., Han, D., \& Niu, L. (2010). Stable, Conductive Supramolecular Composite of Graphene Sheets with Conjugated Polyelectrolyte. Langmuir, 26(9), 6708-6712.

[123] Chunder, ]., Liu, J., \& Zhai, L. (2010). Reduced Graphene Oxide/Poly(3-hexylthiophene) Supramolecular Composites. Macromolecular Rapid Communications, 31(4), 380-384.

[124] Liu, Q., Liu, Z., Zhang, X., Zhang, N., Yang, L., Yin, S., \& Chen, Y. (2008). Organic photovoltaic cells based on an acceptor of soluble graphene. Applied Physics Letters, 92(22), 223303.

[125] Liu, Q., Liu, Z., Zhang, X., Yang, L., Zhang, N., Pan, G., Yin, S., Chen, Y., \& Wei, J. (2009). Polymer photovoltaic cell based on a solution processable graphene and 3HT. Advanced functional material, 19, 894-904.

[126] Kumar, N. A., Choi, H. J., Shin, Y. R., Chang, D. W., Dai, L., \& Baek, J. B. (2012). Polyaniline-Grafted Reduced Graphene Oxide for Efficient Electrochemical Supercapacitors. ACS Nano, 6(2), 1715-1723.

[127] Wang, X., Zhi, L., \& Mullen, K. (2007). Transparent, Conductive Graphene Electrodes for Dye-Sensitized Solar Cells. Nano Letters, 8(1), 323-327.

[128] Yoo, E., Kim, J., Hosono, E., Zhou, H., Kudo, T., \& Honma, I. (2008). Large Reversible Li Storage of Graphene Nanosheet Families for Use in Rechargeable Lithium Ion Batteries. Nano Letters, 8(8), 2277-2282.

[129] Tang, Z., Shen, S., Zhuang, J., \& Wang, X. (2010). Noble-Metal-Promoted Three-Dimensional Macroassembly of Single-Layered Graphene Oxide. Angewandte. Chemie International Edition, 49(27), 4603-4607.

[130] Varrla, E., Venkataraman, S., \& Sundara, R. (2011). Functionalized Graphene-PVDF Foam Composites for EMI Shielding. Macromol. Mater. Eng., 296-894.

[131] Ghasemi, A., Saatchi, A., Salehi, M., Hossienpour, A., Morisako, A., \& Liu, X. (2006). Influence of matching thickness on the absorption properties of doped barium ferrites at microwave frequencies. Phys Status Solidi A, 203, 358-65. 
[132] Xie, J. L., Han, M., Chen, L., Kuang, R., \& Deng, L. (2007). Microwave-absorbing properties of NiCoZn spinel ferrites. J Magn. Magn. Mater, 314-37.

[133] Lu, B., Dong, X. L., Huang, H., Zhang, X. F., Zhu, X. G., \& Lei, J. P. (2008). Microwave absorption properties of the core/shell-type iron and nickel nanoparticles. J. Magn. Magn. Mater, 320-1106.

[134] Liu, X. G., Geng, D. Y., Meng, H., Shang, P. J., \& Zhang, Z. D. (2008). Microwave-absorption properties of ZnO-coated iron nanocapsules. Appl Phys Lett, 92(173117).

[135] Li, B. W., Shen, Y., Yue, Z. X., \& Nan, C. W. (2006). Enhanced microwave absorption in nickel/hexagonal-ferrite/polymer composites. Appl Phys Lett, 89(132504).

[136] Che, R. C., Zhi, C. Y., Liang, C. Y., \& Zhou, X. G. (2006). Fabrication and microwave absorption of carbon nanotubes/CoFe2O4 spinel nanocomposite. Appl Phys Lett, 88(033105).

[137] Watts, P. C. P., Hsu, W. K., Barnes, A., \& Chambers, B. (2003). High permittivity from defective multiwalled carbon nanotubes in the X-band. Adv Mater, 15-600.

[138] Xu, H., Anlage, S. M., Hu, L., \& Grunera, G. (2007). Microwave shielding of transparent and conducting single-walled carbon nanotube films. Appl Phys Lett, 90, 183119.

[139] Singh, K., Ohlan, A., Bakhshi, A. K., \& Dhawan, S. K. (2010). Synthesis of conducting ferromagnetic nanocomposite with improved microwave absorption properties. $M a-$ ter. Chem. Phys., 119, 201-7.

[140] Ohlan, A., Singh, K., Chandra, A., \& Dhawan, S. K. (2010). Microwave absorption behavior of core-shell structured poly (3,4-ethylenedioxy thiophene)-barium ferrite nanocomposites. ACS Appl. Mater. Interfaces, 2, 927-33.

[141] Singh, K., Ohlan, A., Saini, P., \& Dhawan, S. K. (2008). Poly (3,4-ethylenedioxythiophene) $\gamma$-Fe2O3 polymer composite-super paramagnetic behavior and variable range hopping 1D conduction mechanism-synthesis and characterization. Polym. Adv. Technol, 19, 229-36.

[142] Zhang, X. F., Dong, X. L., Huang, H., Liu, Y. Y., Wang, W. N., \& Zhu, X. G. (2006). Microwave absorption properties of the carbon-coated nickel nanocapsules. Appl Phys Lett., 89, 053115.

[143] Tang, N., Zhong, W., Au, C., Yang, Y., Han, M., \& Lin, K. (1992). Synthesis, microwave electromagnetic, and microwave absorption properties of twin carbon nanocoils. J Phys Chem., C112, 19316-23.

[144] Colaneri, N. F., \& Shacklette, L. W. (1992). EMI shielding measurements of conductive polymer blends. IEEE Trans Instru Meas, 41, 291-7.

[145] Singh, R., Kumar, J., Singh, R. K., Rastogi, R. C., \& Kumar, V. (2007). Low frequency ac conduction and dielectric relaxation in pristine poly(3 -octylthiophene) films. New J Phys, 9-40. 
[146] Nicolson, A. M., \& Ross, G. F. (1970). Measurement of the intrinsic properties of materials by time-domain techniques. IEEE Trans Instrum Meas, 19-377.

[147] Weir, ]., \& , W. B. (1974). Automatic measurement of complex dielectric constant and permeability at microwave frequencies. Proceedings of the IEEE, 62-33.

[148] Ishino, K., \& Narumiya, Y. (1987). Development of magnetic ferrites: control and application of losses. Ceram Bull, 66-1469.

[149] Dimitrov, D. A., \& Wysin, G. M. (1995). Magnetic properties of spherical fcc clusters with radial surface anisotropy. Phys Rev B, 51(11947).

[150] Shilov, V. P., Bacri, J. C., Gazeau, F., Gendron, F., Perzynski, R., \& Raikher, Y. L. (1999). Ferromagnetic resonance in ferrite nanoparticles with uniaxial surface anisotropy. J Appl Phys., 85(6642).

[151] Basavaraja, C., Kim, W. J., Kim, Y. D., \& Huh, D. S. (2011). Synthesis of polyanilinegold/graphene oxide composite and microwave absorption characteristics of the composite films. Materials Letters, 65(19-20), 3120-3123.

[152] Liu, D. Y., \& Reynolds, J. R. (2010). Dioxythiophene-Based Polymer Electrodes for Supercapacitor Modules. ACS Applied Materials \& Interfaces, 2(12), 3586-3593. 
